\title{
Shock Characteristics of the Opposed Disc Springs (ODS) Shock Isolator with Pretightening under Boundary Friction Condition
}

\author{
An-Min Hui $\mathbb{D}^{1},{ }^{1}$ Ming Yan $\mathbb{D}^{1},{ }^{1}$ Lei Zhang $\mathbb{D}^{2},{ }^{2}$ Ying-Li Jin $\mathbb{D}^{1},{ }^{1}$ Kaiping Wang $\left(\mathbb{D},{ }^{1}\right.$ \\ and Haichao Liu $\mathbb{D}^{1}$ \\ ${ }^{1}$ College of Mechanical Engineering, Shenyang University of Technology, Shenyang 110870, China \\ ${ }^{2}$ Naval Research Academy, Beijing 100161, China \\ Correspondence should be addressed to Ming Yan; yanming7802@163.com
}

Received 6 January 2021; Revised 20 March 2021; Accepted 26 March 2021; Published 23 April 2021

Academic Editor: Francesco Pellicano

Copyright (C) 2021 An-Min Hui et al. This is an open access article distributed under the Creative Commons Attribution License, which permits unrestricted use, distribution, and reproduction in any medium, provided the original work is properly cited.

In this study, to solve the problems of shock environment and shock isolation, about which there is still a lack of reasonable description, an isokinetic shock distinguishing method (ISDM), which can quantitatively distinguish between shock and forced vibration state, is presented. And the shock isolation performance of an opposed disc springs (ODS) shock isolator with pretightening under boundary friction condition is investigated. The static and dynamic stiffness properties of the ODS shock isolator are discussed. Relying on ISDM, a shock dynamic model of the ODS shock isolator with pretightening under boundary friction condition is established. The average method is adopted to solve the model theoretically. The shock acceleration ratio (SAR), shock displacement ratio (SDR), and relative displacement ratio (RDR) of the model are calculated using the numerical method and verified by experiments. Both numerical and experimental results show that ISDM is effective. And the effects on isolation efficiency of the number of disc springs, additional supporting force, pretightening force, load, and the shock velocity constant of the ODS shock isolator are discussed, which provide guidelines for its further practical application.

\section{Introduction}

Shock is a general problem existing in various occasions, such as landing of aircraft, firing of artillery and missiles, sudden undulation of road surface in transportation, explosions caused by the attack of weapons on ships, and earthquake. Usually, shock is defined as the transient excitation experienced by a system and sudden changes in its force, displacement, velocity, or acceleration [1]. How to reduce the damage caused by shock to equipment and personnel is a common engineering problem [2]. In general, the basic rule of shock isolation is that when shock occurs, the energy of shock is stored by the elastic element of the shock isolation system and quickly dissipated through its damping element, and residual vibration is reduced as much as possible. The fundamental theory of shock analysis and isolation, which basically deals with linear systems, has been studied in $[3,4]$. Passive nonlinear isolation systems capable of resolving the contradiction between bearing capacity and low natural frequency of linear systems have been attracting extensive attention. In particular, in terms of shock isolation, nonlinear isolation systems with soft characteristic stiffness and less damping have better shock isolation performance than linear isolation systems $[5,6]$. In recent years, in view of the excellent vibration isolation performance of quasizero stiffness isolation systems, many scholars have conducted extensive research on them and applied them in various fields [7-10]. Especially, there is a mature method to realize the quasizero stiffness characteristic by using semiactive control [11]. It is also found that quasizero stiffness isolation systems have better shock isolation performance for shock excitation with low amplitude [12]. However, notwithstanding the ability of a low-stiffness structure to absorb the energy of shock and vibration efficiently, it is very sensitive to external excitation load and has poor robustness at the static equilibrium position of the system. This may affect the normal operation of the device. Moreover, the response displacement caused by shock in practical engineering is generally much larger than the effectively protection displacement by low-stiffness isolation systems. 
The study by Duan and Singh [13] has shown that an elastic element with a certain initial pretightening force can effectively improve the stability of the isolator at the static equilibrium position, and it is held that nonlinear elastic elements can endow a shock isolation system with greater rigidity at the static equilibrium position. This ensures that the equipment and the base remain relatively stationary when the system is subjected to low-frequency and smallamplitude disturbances and that the shock isolator maintains a good shock isolation effect when the system is subjected to a high shock load. A disc spring, as the elastic element of isolation systems, is characterized by small size, high bearing capacity, uniform loading, variable stiffness, superior isolation performance, and self-damping. Multiple disc springs can be combined in different stacking ways to form a variety of nonlinear elastic elements with different stiffness. Elements of this type have the damping characteristics of Coulomb and viscous damping due to the deformation of disc springs [14]. Therefore, this study presents an ODS shock isolator with pretightening, which ensures a good shock isolation effect and stability at the static equilibrium position and can be applied in strong shock environment with large displacement response.

At present, many scholars have performed significant analysis and research on disc springs and vibration isolation devices with disc springs. Theoretical analysis and calculation research have been carried out on conical disc springs with equal cross-section by Almen and Laszlo [15]. They found that the internal structure had the minimized Coulomb damping coefficient when disc springs had opposite forms. The calculation relationship between the geometric properties of disc springs and the bearing capacity was also given. Relying on the theoretical research of Rosa and Messina [16] and Saini et al. [17], the relationship between the bearing capacity and deformation of disc springs with linear varying and parabolic cross-sections through calculation and analysis, respectively, is investigated. Ozaki et al. [18] performed static and dynamic analysis on the friction boundary of disc springs using the numerical method. Patangtalo et al. [19] and Fawazi et al. [20] also used the numerical method to study the load-displacement curves of combined disc springs and slotted disc springs. Gao and Yang [21] established a nonlinear stiffness model of disc springs element to meet the shock and vibration isolation requirements of the artillery system and explored the vibration isolation performance of this model.

Thus far, the expression of shock is only transient and intense excitation. It is often reported that the severity parameter is used to describe the severity of shock, but the response performance of the system after shock is closer to the response performance of forced vibration with the decrease of the severity parameter $[22,23]$. So there is a lack of reasonable quantitative expression about the shock and the forced vibration. When calculating the shock response, the shock load is often equivalent to the step velocity as the shock input. Therefore, there is also little reasonable description of shock environment or shock isolation. At the same time, as a nonlinear elastic element, disc springs have excellent nonlinear shock isolation performance. However, existing studies mostly focus on static performance, quasistatic performance under boundary friction conditions of single disc springs, and theoretical research and simulation analysis on the loading processes of conventional and special-shaped disc springs. The analysis of the isolation system in combination with disc springs is also limited to its equivalent linear model or nonlinear vibration characteristics. And few references have investigated the thorough shock isolation performance of the isolator with disc springs, especially the effects of pretightening, boundary friction, load-bearing, and other factors on shock isolation performance. These factors are of great importance for the further practical application of shock isolators with disc springs.

This study is organized as follows: an ODS shock isolator with pretightening is developed, and its shock isolation performance theoretically and experimentally is investigated. In Section 2, the structure of the ODS shock isolator is introduced, and its static stiffness, dynamic stiffness, and stiffness characteristics under boundary friction conditions are theoretically investigated. In Section 3, ISDM is presented. The effects of different systems on ISDM are explored, and then, the shock state of the system is quantitatively distinguished the other states. In Section 4, the shock isolation performance of the ODS shock isolator under base excitation of ISDM is explored though mathematical simulation. The effects of the number of disc springs, additional supporting force, pretightening force, load, and the shock velocity constant on ODS shock isolator are discussed. In Section 5, shock isolation experiments of ODS shock isolator under base excitation of ISDM with different shock velocity constants are performed using a drop shock test table, which validates the simulation results. Conclusions are drawn in Section 6.

\section{Structure and Stiffness Characteristics of the ODS Shock Isolator}

The ODS shock isolator (Figure 1(a)) is mainly composed of several opposed disc springs (ODS). A structural feature of the shock isolator is that ODS are placed in series as elastic elements. Flat washers are arranged at the contact surfaces of opposed disc springs to ensure sufficient friction and uniform stress during tension and compression (Figure 1(b)). The disc spring is an A-series unsupported disc spring made of $60 \mathrm{Si} 2 \mathrm{MnA}$. In the initial state, pretightening is applied on the ODS shock isolator to ensure high static and low dynamic stiffness characteristics. Depending on different loading conditions, the initial pretightening force of the ODS shock isolator can be regulated through adjusting the thickness of the pressure plate. An appropriate amount of silicone oil is applied between the upper and lower pressure plates for lubrication. The axial tension and pressure transmitted from the outside to the ODS shock isolator can be converted into the pressure on ODS, thus ensuring a compact structure and an inseparable ODS unit.

Another special feature of the shock isolator is that the system has a strong ability to resist microdisturbance caused by the pretightening force. The base and the isolation equipment are connected rigidly when the base is 


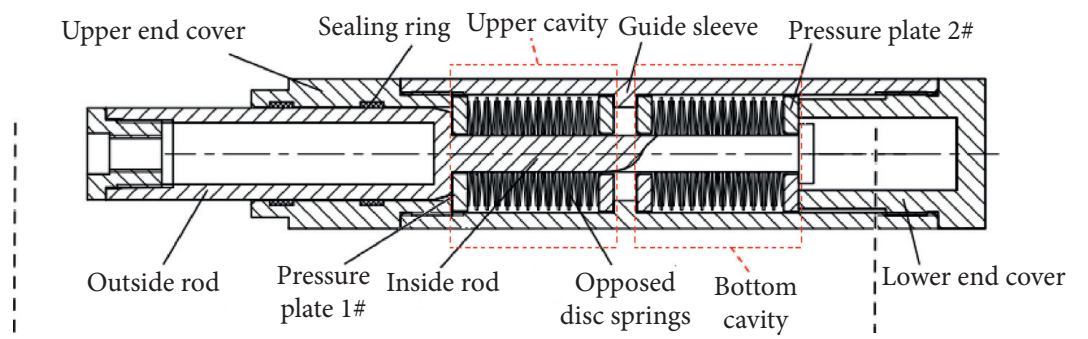

The maximum point of the upper stroke

The maximum point of the down stroke

(a)

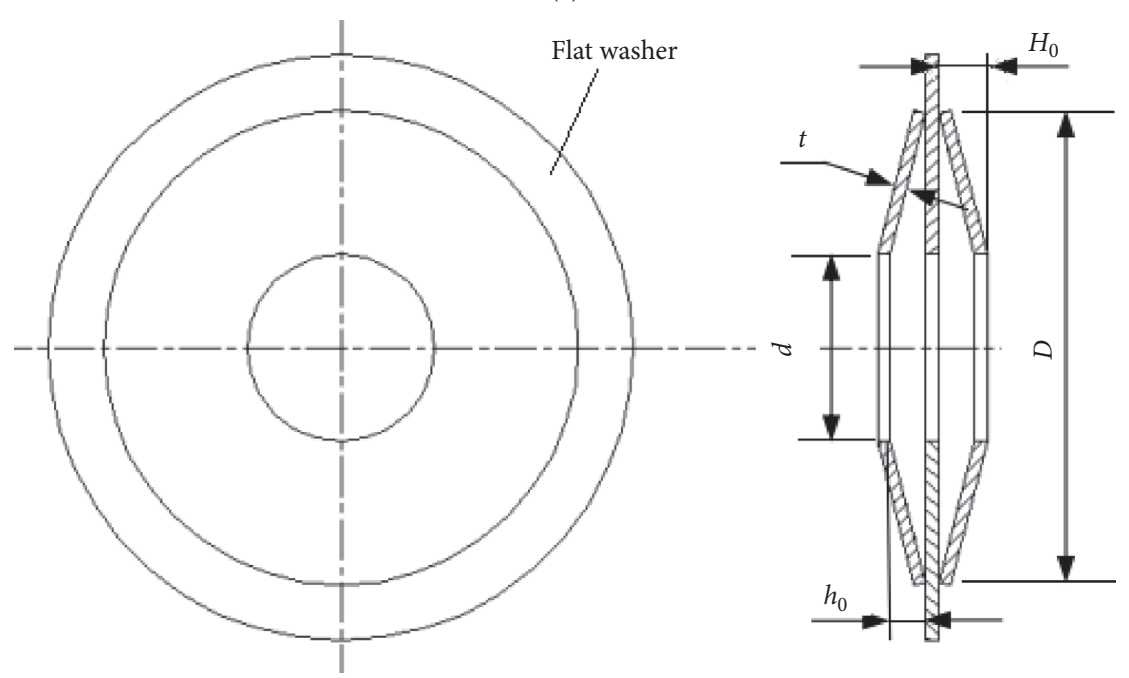

(b)

FIGURE 1: Schematic diagram of the floating shock platform. (a) Schematic diagram of the ODS shock isolator. (b) ODS unit.

affected by small-amplitude and low-frequency excitation. At this time, the external excitation force is within the limit range of the equipment and will not cause damage to the equipment. The shock isolator appears to have a shock isolation effect when the excitation force with high amplitude is greater than the preset pretightening force. The preloaded ODS in the upper cavity are compressed to the maximum point of the downstroke by the downward outside rod and the pressure plate $1 \#$. Then, the system returns to the static equilibrium position under the elastic force of the ODS in the upper cavity. Under the action of inertia, the preloaded ODS in the bottom cavity are compressed to the maximum point of the upper stroke by the upward inside rod and the pressure plate 2\#. Similarly, under the elastic force of the ODS in the bottom cavity, the system returns to the static equilibrium position, and the single periodic movement is completed. The system will move periodically according to the above rules until the energy from external excitation is exhausted through Coulomb and viscous damping of ODS. One advantage of this design is that the force of external load is converted into the axial pressure on the ODS by this isolator, regardless of the axial tension or pressure transmitted from the outside to the shock isolation system. This also ensures high reset precision after shock.
2.1. Static and Dynamic Stiffness Characteristics of the ODS Shock Isolator. According to the theory presented by Almen and Laszlo [15], the derivation of the bearing load and deformation of the disc spring must meet the following three assumptions: the cross-section of the disc spring does not distort, but merely rotates about a neutral point. The loads are concentrically distributed, the radial stresses are negligible, and the material property of the disc springs is completely elastic. The friction between contact surfaces is ignored. Therefore, the theoretical calculation formula for the elastic force and deformation of the A-series disc spring without support surface is as follows:

$$
F_{k}=\frac{4 E}{\left(1-\mu^{2}\right)} \cdot \frac{t^{4}}{D^{2}} \cdot \frac{f}{t}\left[\left(\frac{h_{0}}{t}-\frac{f}{t}\right)\left(\frac{h_{0}}{t}-\frac{f}{2 t}\right)\left(\frac{1}{K_{1}}\right)+\left(\frac{1}{K_{1}^{\prime}}\right)\right],
$$

where $\quad K_{1}=(1 / \pi)\left(((C-1) / C)^{2} /((C+1) /(C-1))-(2 /\right.$ $\ln C)), K_{1}^{\prime}=\left(6((C-1) / C)^{2} / \pi \ln C\right), F_{k}$ is the elastic force provided by the disc spring, $E$ is the elastic modulus, $\mu$ is Poisson's ratio, $f$ is the deformation amount of the disc spring, $C$ is the diameter ratio of the disc spring, and the value is $C=D / d$.

In order to reduce calculation load, equation (1) can be simplified as the following equation for calculation: 


$$
F_{k}=\frac{4 E}{\left(1-\mu^{2}\right)} \frac{t^{4}}{K_{1} D^{2}} \frac{f}{t}\left[\left(\frac{h_{0}}{t}-\frac{f}{t}\right)\left(\frac{h_{0}}{t}-\frac{f}{2 t}\right)+1\right] .
$$

The pressure and deformation curves (axial displacements) of single disc springs with different thicknesses are shown in Figure 2. These disc springs have an outer diameter $D=28 \mathrm{~mm}$, an inner diameter $d=10 \mathrm{~mm}$, a free height $H_{0}=1.15 \mathrm{~mm}$, and a flattening height $h_{0}=0.7 \mathrm{~mm}$ (the relevant geometric parameters of disc springs mentioned below are the same here). It can be seen that the bearing capacity of a disc spring is positively related to its thickness. If a disc spring is thin, there will be a negative stiffness region near the flattening displacement, and the thinner the disc spring, the larger the negative stiffness region. However, if the thickness of the disc spring increases, the negative stiffness region will gradually disappear.

According to the structure of ODS, these disc springs are connected in series. Therefore, under the same load, the displacement of the ODS shock isolator is $n$ times that of a single disc spring, and the stiffness becomes $1 / n$ times that of a single disc spring, where $n$ is the number of disc springs in the ODS shock isolator. The dynamic stiffness of the ODS shock isolator is defined as

$$
k_{r}=\frac{\Delta F_{k}}{\Delta s},
$$

where $\Delta F$ is the increment of the elastic force, $\Delta s$ is the axial displacement increment of the ODS shock isolator, and its value is $n \Delta f$.

Figures 3(a) and 3(b) show the force-displacement diagram and dynamic stiffness curve of the ODS shock isolator with different numbers and thicknesses of disc springs. It can be seen that, given the thickness of the disc springs in the system, with the increase of the number $n$ of the disc springs, the bearing capacity of the ODS shock isolator increases and the initial dynamic stiffness decreases, but the decline of dynamic stiffness slows down. Similarly, with the increase of the thickness of the disc springs, the bearing capacity of the ODS shock isolator increases, and the dynamic stiffness intersection points with different numbers of disc springs move towards the direction of large displacement. The relationship between the elastic force and the axial displacement $x$ for the ODS shock isolator can be accurately fitted by a cubic function:

$$
F_{k}=k_{1} x+k_{2} x^{2}+k_{3} x^{3}
$$

The fitting coefficients are denoted by $k_{1}, k_{2}$, and $k_{3}$.

To investigate its effects on static stiffness, the variation of the ratio of dynamic stiffness to static stiffness with displacement, and the shock performance of the ODS shock isolator, pretightening force $F_{c}$ is set as $15 \mathrm{~N}, 30 \mathrm{~N}$, $45 \mathrm{~N}$, and $60 \mathrm{~N}$ and the thickness of the disc springs as $0.5 \mathrm{~mm}$, respectively. Theoretically, the smaller the ratio of dynamic stiffness to static stiffness is, the better the lowfrequency isolation performance of the nonlinear isolator is [2]. Figures 4(a)-4(d) show the force-displacement curve of the ODS shock isolator under different pretightening forces

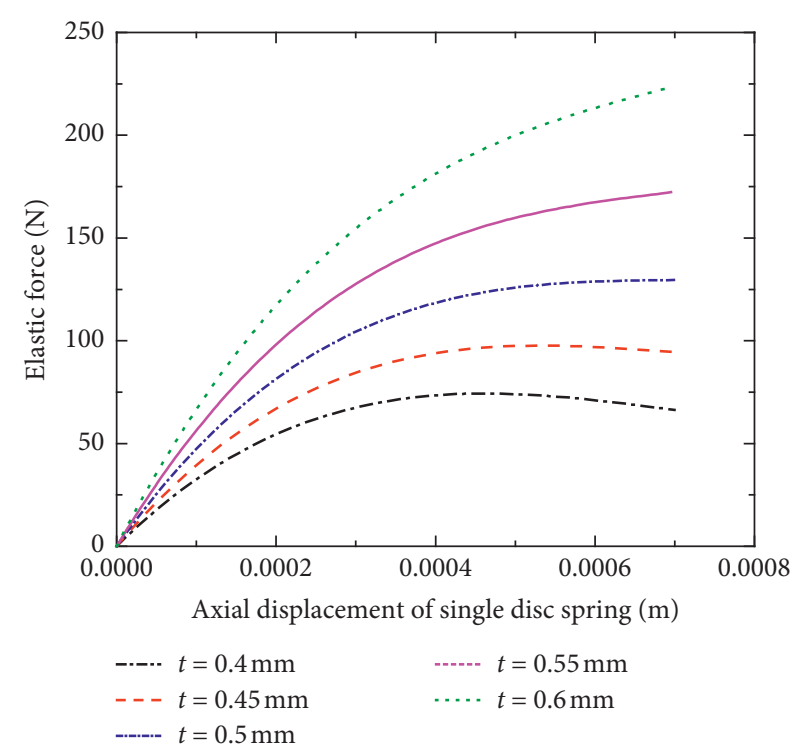

FIgURE 2: The pressure and deformation curves (axial displacements) of single disc springs with different thicknesses.

and the variation rule of the ratio of dynamic stiffness to static stiffness with displacement. It can be seen that, with the increase of the displacement of the ODS shock isolator, the ratio of dynamic stiffness to static stiffness first increases and then decreases, and the maximum value appears around the displacement of $0.005 \mathrm{~m}$. With the increase of the number $n$ of the disc springs, the maximum value of the ratio of dynamic stiffness to static stiffness moves to the direction of large displacement. When the pretightening of the ODS shock isolator is increased, the variation rule of the ratio of dynamic stiffness to static stiffness remains almost constant with the change of displacement, but the peak values decrease. Therefore, it can be obtained that the low-frequency vibration isolation performance of the ODS shock isolator changes with displacement. The low-frequency vibration isolation performance of the ODS shock isolator under small and large displacement vibrations is obviously better than that under vibrations with an amplitude of $0.005 \mathrm{~m}$, and with the increase of pretightening, vibration isolation performance of the ODS shock isolator is improved. For ODS with different thicknesses, the variation rules of stiffness and isolation performance are similar to those described above.

\subsection{Effect of Boundary Friction on the ODS Shock Isolator.} Since each pair of ODS has four joint surfaces and friction is generated between each combination of joint surfaces, when the number $n$ of the disc springs is sufficiently large, the friction generated between joint surfaces should not be ignored. According to the analysis of friction dissipation during disc spring loading in [18], the diagram of the force principle of a single disc spring during axial loading is shown in Figure 5.

In this figure, $l$ is the diagonal length of the cross-section of the disc spring, $\theta$ is the angle between the normal of the 


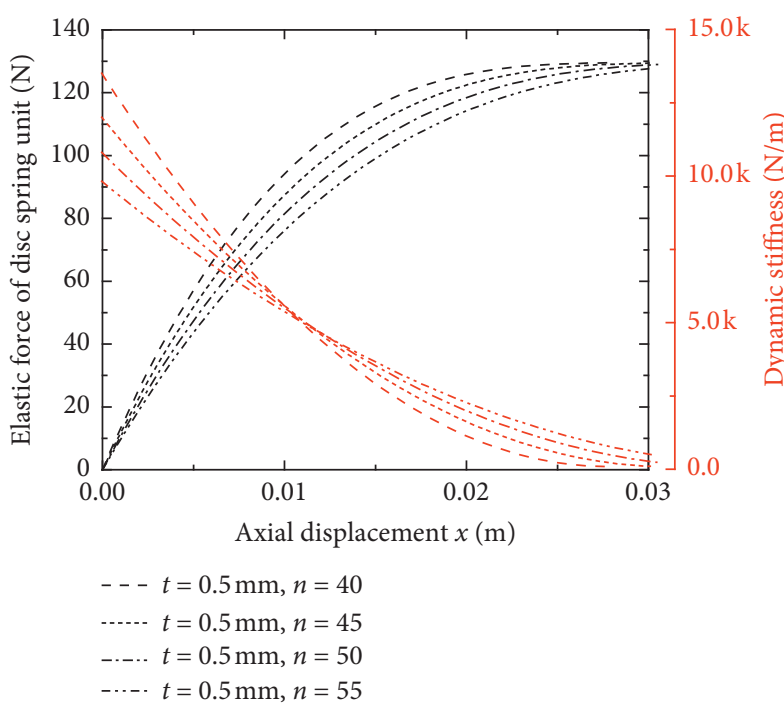

(a)

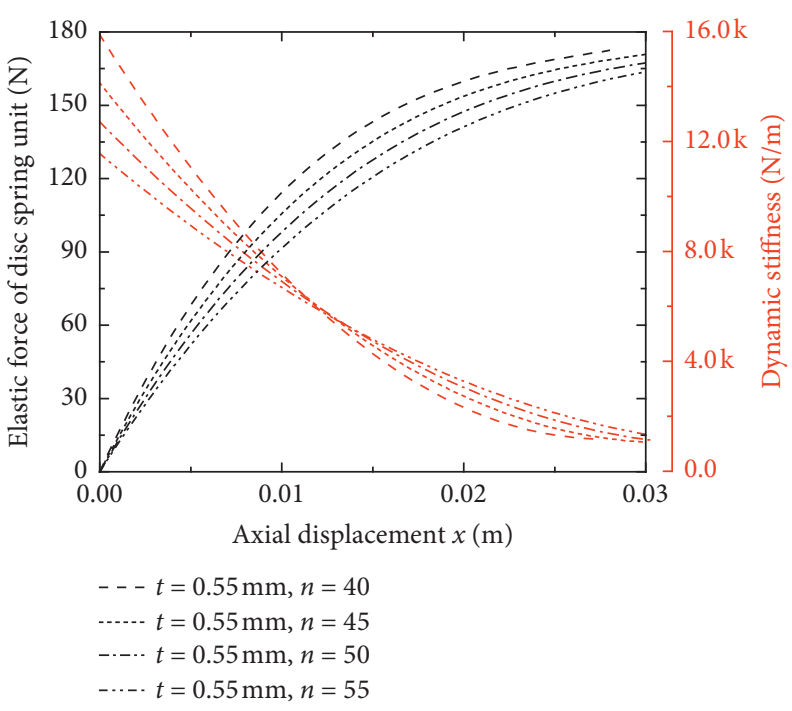

(b)

Figure 3: Force-displacement diagram and dynamic stiffness curve. (a) The thickness of the disc spring is $0.5 \mathrm{~mm}$. (b) The thickness of the disc spring is $0.55 \mathrm{~mm}$.

constraint surface and the diagonal of the cross-section of the disc spring, $\alpha$ is the rotation angle of the disc spring section around the neutral point $O, F_{f}$ is the friction force generated by the contact surface after compression under load, $\mu_{e}$ is the coefficient of system friction, and $u_{e}$ is the horizontal sliding distance of the disc spring.

The geometric relationship between the deformation of the disc spring and its horizontal sliding distance is approximated by the following equation:

$$
\begin{gathered}
u_{e}=\frac{1}{2} \sqrt{2 l^{2}(1-\cos \alpha)-f^{2}}, \\
\alpha=\arccos \left(\cos \theta-\frac{f}{l}\right)-\theta .
\end{gathered}
$$

Thus, the relationship between the energy increment $\Delta E$ of the friction loss and its horizontal sliding distance increment is as follows:

$$
\Delta E=2 F_{f} \Delta u_{e}=2 F \mu_{e} \Delta u_{e}
$$

According to equation (6), under the boundary friction condition, the additional supporting force $F_{\mu i}$ provided by the friction force is

$$
F_{\mu i}=\frac{\Delta E}{\Delta f}
$$

Therefore, under different friction coefficients, the relation curve between axial compression distance $f$ and the additional support force $F_{\mu i}$ during loading and unloading of a single disc spring is shown in Figure 6, where the thickness of the disc spring $t=0.5 \mathrm{~mm}$.

The relationship between addition supporting forceaxial compression distance $(f=(x / n))$ can be accurately fitted by a cubic polynomial function:

$$
F_{\mu i}=k_{f 1}\left(\frac{x}{n}\right)+k_{f 2}\left(\frac{x}{n}\right)^{2}+k_{f 3}\left(\frac{x}{n}\right)^{3} .
$$

The fitting coefficients are denoted by $k_{f 1}, k_{f 2}$, and $k_{f 3}$, and the specific values are given in Table 1.

It is assumed that the compression displacement of the ODS shock isolator is $x_{s}$ when this system is preloaded. Then, according to equations (4) and (8), the sum of the initial bearing capacity $F_{r}$ of the ODS shock isolator considering the friction between the disc springs and the additional support force provided by the disc spring can be obtained.

$$
\begin{array}{r}
F_{r}=\left(k_{1}+k_{f 1}\right) x_{s}+\left(k_{2}+\frac{k_{f 2}}{n}\right) x_{s}^{2}+\left(k_{3}+\frac{k_{f 3}}{n^{2}}\right) x_{s}^{3}, \\
\sum_{i=1}^{n} F_{\mu i}\left(x+x_{s}\right)=k_{f 1}\left(x+x_{s}\right)+\frac{k_{f 2}}{n}\left(x+x_{s}\right)^{2}+\frac{k_{f 3}}{n^{2}}\left(x+x_{s}\right)^{3} .
\end{array}
$$

So under considering the condition of initial bearing capacity $F_{r}$ and the boundary friction conditions, the total load of

$$
F(x)=F_{k}\left(x+x_{s}\right)+\sum_{i=1}^{n} F_{\mu i}\left(x+x_{s}\right) .
$$
the ODS shock isolator is shown in the following equation: 

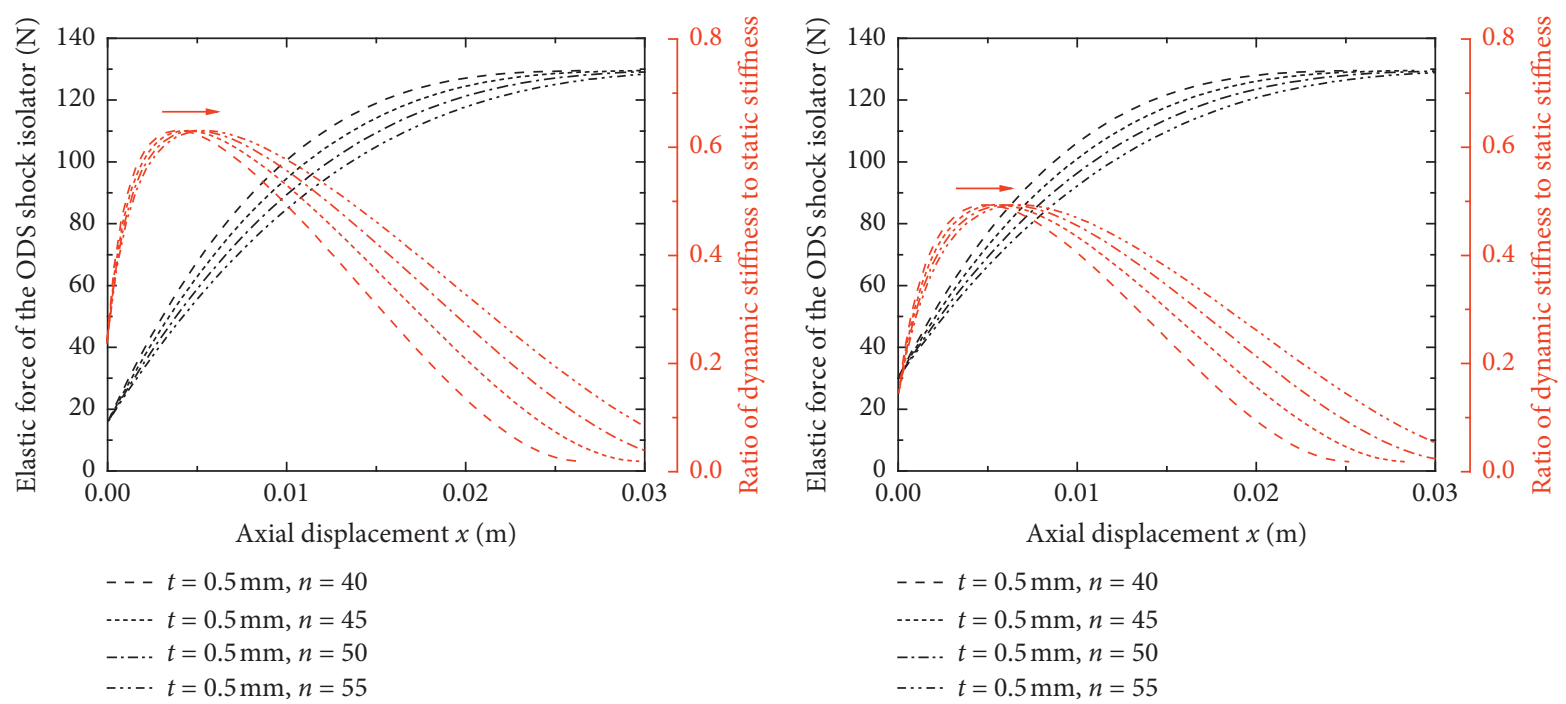

(a)

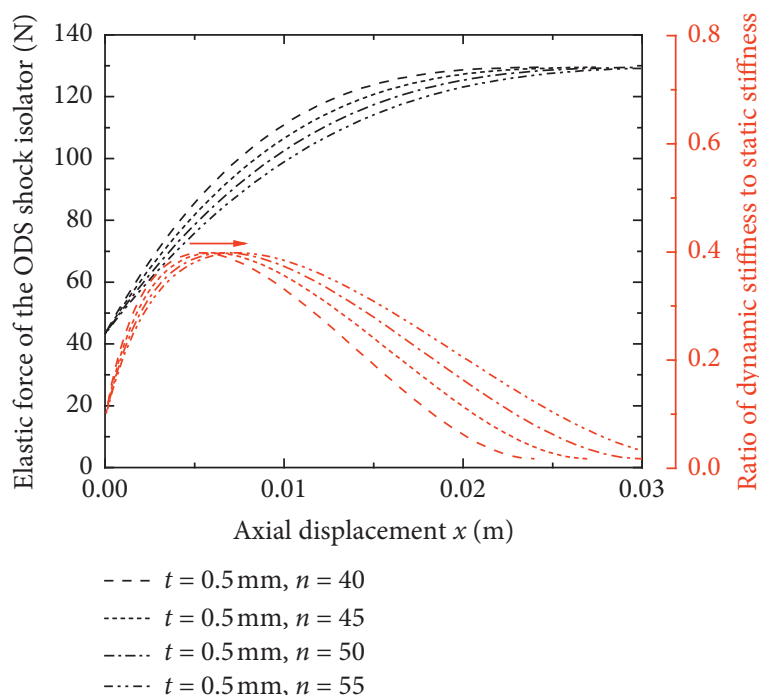

(c) (b)

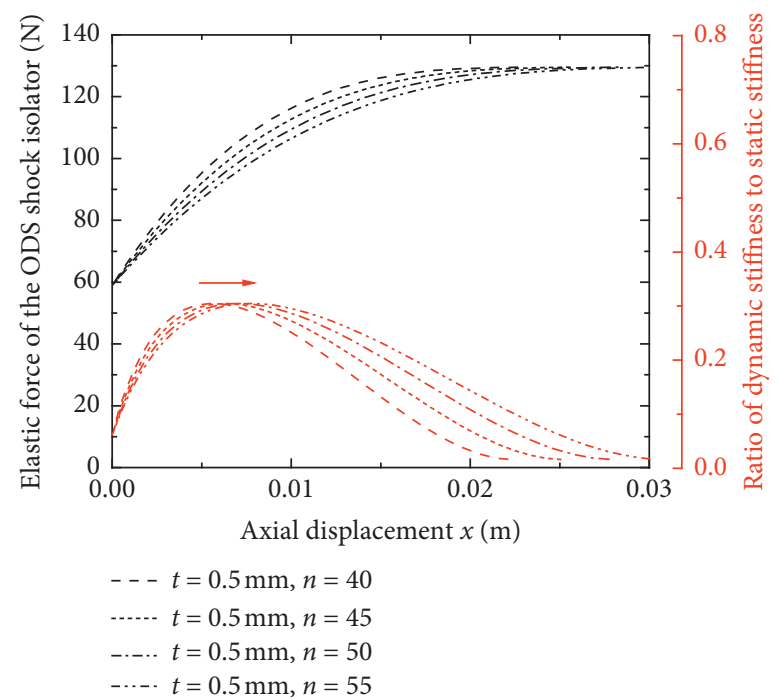

(d)

FIgURE 4: The force-displacement curve of the ODS shock isolator under different pretightening forces and the variation rule of the ratio of dynamic stiffness to static stiffness with displacement. (a) Pretightening force is 15 N. (b) Pretightening force is 30 N. (c) Pretightening force is $45 \mathrm{~N}$. (d) Pretightening force is $60 \mathrm{~N}$.

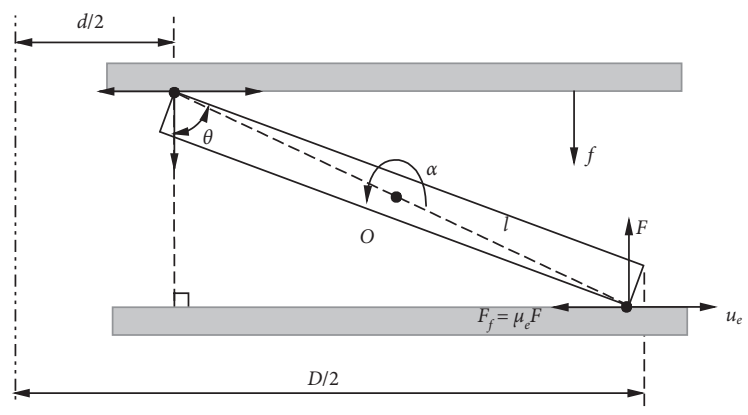

FIgURE 5: Diagram of the force principle of a single disc spring during axial load. 


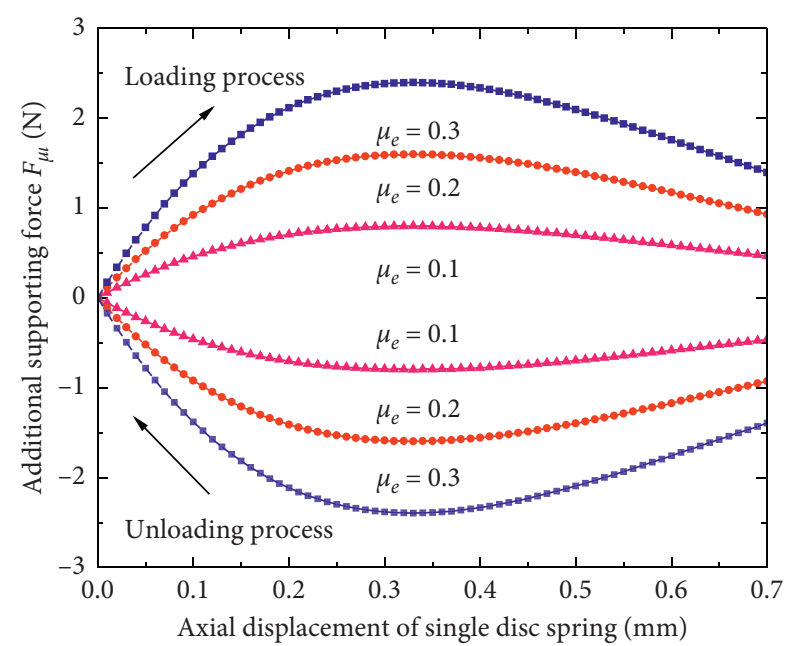

FIGURE 6: Relationship between additional load and displacement.

TABle 1: Fitting coefficient of additional supporting force-compression distance curve.

\begin{tabular}{cccc}
\hline$\mu_{e}$ & $k_{f 1}$ & $k_{f 2}$ & $k_{f 3}$ \\
\hline 0.1 & 5661 & $-1.21 \times 10^{7}$ & $7.18 \times 10^{9}$ \\
0.2 & 11322.34 & $-2.43 \times 10^{7}$ & $1.44 \times 10^{10}$ \\
0.3 & 16983.52 & $-3.64 \times 10^{7}$ & $2.15 \times 10^{10}$ \\
\hline
\end{tabular}

Therefore, when the ODS shock isolator is in the loading state, the direction of the additional supporting force caused by friction is consistent with the direction of the spring force of the disc springs. At this time, the bearing capacity increases and the stiffness of the ODS shock isolator increases. When the ODS shock isolator is in the unloading state, the direction of the additional supporting force caused by friction is opposite to the direction of the spring force of the disc springs, and the stiffness of the ODS shock isolator decreases. These lead to that the ODS shock isolator generate hysteresis characteristics.

The relationship between the elastic force $F_{k}$ and the axial displacement $x$ curve of the ODS shock isolator under different pretightening forces and the number of the disc springs can be accurately fitted by a cubic polynomial function, where the thickness $t$ of the disc springs is $0.5 \mathrm{~mm}$.

$$
F_{k}=K_{1} x+K_{2} x^{2}+K_{3} x^{3}+\beta .
$$

The specific values are given in Table 2:

\section{Isokinetic Shock Distinguishing Method (ISDM)}

For the shock isolation system with base excitation, the shock excitation has a short duration, and the shock input is over before the system response reaches the maximum value. After that, the system is in a state of attenuation of free vibration. This process can be seen as during the duration of the shock, the shock isolation system is in the forced vibration state, and after the shock is over, the system is in a damped free vibration attenuation state [24]. To simplify the analysis process of shock, in the theoretical analysis process, most [25-27] equates shock
TABLE 2: Fitting coefficient of elastic force and axial displacement of the shock isolator.

\begin{tabular}{cccccc}
\hline$n$ & $F_{c}(\mathrm{~N})$ & $K_{1}$ & $K_{2}$ & $K_{3}$ & $\beta$ \\
\hline \multirow{4}{*}{45} & 30 & $1.02 \times 10^{4}$ & $-3.51 \times 10^{5}$ & $4.06 \times 10^{6}$ & 30 \\
& 45 & $9.27 \times 10^{3}$ & $-3.35 \times 10^{5}$ & $4.06 \times 10^{6}$ & 45 \\
& 60 & $8.10 \times 10^{3}$ & $-3.13 \times 10^{5}$ & $4.06 \times 10^{6}$ & 60 \\
\hline \multirow{4}{*}{50} & 30 & $9.17 \times 10^{3}$ & $-2.84 \times 10^{5}$ & $2.96 \times 10^{6}$ & 30 \\
& 45 & $8.34 \times 10^{3}$ & $-2.71 \times 10^{5}$ & $2.96 \times 10^{6}$ & 45 \\
& 60 & $7.29 \times 10^{3}$ & $-2.53 \times 10^{5}$ & $2.96 \times 10^{6}$ & 60 \\
\hline \multirow{4}{*}{55} & 30 & $8.34 \times 10^{3}$ & $-2.35 \times 10^{5}$ & $2.22 \times 10^{6}$ & 30 \\
& 45 & $7.58 \times 10^{3}$ & $-2.24 \times 10^{5}$ & $2.22 \times 10^{6}$ & 45 \\
& 60 & $6.63 \times 10^{3}$ & $-2.09 \times 10^{5}$ & $2.22 \times 10^{6}$ & 60 \\
\hline
\end{tabular}

excitation with an ideal step velocity load. But, such an equivalent process inevitably leads to errors in the calculation results. It can be seen that the transient process of shock is a special strong forced vibration process. However, there are essential differences between shock and forced vibration in dynamic and response characteristics. As we all know, few documents can effectively distinguish between the shock state and force vibration state of a system. Therefore, shock state and shock isolation problems still lack a reasonable description. In this section, an isokinetic shock distinguishing method (ISDM), which can quantitatively describe the difference between shock state and other states, is presented.

The isokinetic shock model is established as shown in Figure 7 , where $m_{1}$ and $m_{2}$ are the masses of the isolated object and the base, respectively. $k$ and $c$ are the stiffness of the elastic element and the damping coefficient of the damping element in the shock isolation system, the shock excitation acts on the base, $x$ and $y$, respectively, represent the absolute displacement values of the isolated object and the base after shock excitation, $\delta$ is the relative displacement between the isolated object and the base, and its value is $\delta=x-y$.

Acceleration time-domain curves of a set of shock loads in the abovementioned isokinetic shock model are shown in Figure 8 . The curves I-V are standard half-sine acceleration shock signals with different peak values and duration time, and it is guaranteed that the following equation is constant.

$$
\int_{0}^{\left(\pi / \omega_{0}\right)} \ddot{y}_{i \max } \sin \left(\omega_{0} T\right) \mathrm{d} T=C, \quad i=\mathrm{I}, \ldots, V,
$$

where $\omega_{0}$ and $T$ are the angular frequency and duration time of the half-sine acceleration shock signals, $C$ is the velocity constant after integration, and its value represents the final velocity of the base $m_{2}$ of the shock isolation system at the end of the shock.

According to the isokinetic shock model, the motion differential equation of the system can be written as follows:

$$
m_{1} \ddot{\delta}+c \dot{\delta}+k_{\delta 1} \delta+k_{\delta 2} \delta^{3}=\left\{-m_{1} \ddot{y}_{\max } \sin \left(\omega_{0} T\right), 0<T \leq \frac{\pi}{\omega_{0}}, 0, T>\frac{\pi}{\omega_{0}},\right.
$$

where $k_{\delta 1}$, and $k_{\delta 2}$ are the linear and nonlinear coefficients of the stiffness of the shock isolation system, respectively. The following dimensionless parameters are introduced: $\omega_{n}^{2}=\left(k_{\delta 1} / m_{1}\right), \omega_{n} \cdot T=\tau, \varepsilon=\left(c / m_{1} \cdot \omega_{n}\right), \ddot{\bar{\delta}}=(\ddot{\delta} / g), \dot{\bar{\delta}}=(\dot{\delta}$ 


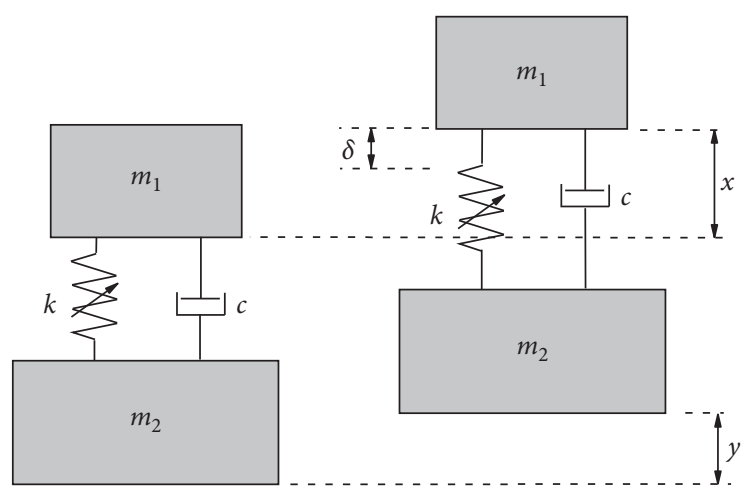

Figure 7: The isokinetic shock model.

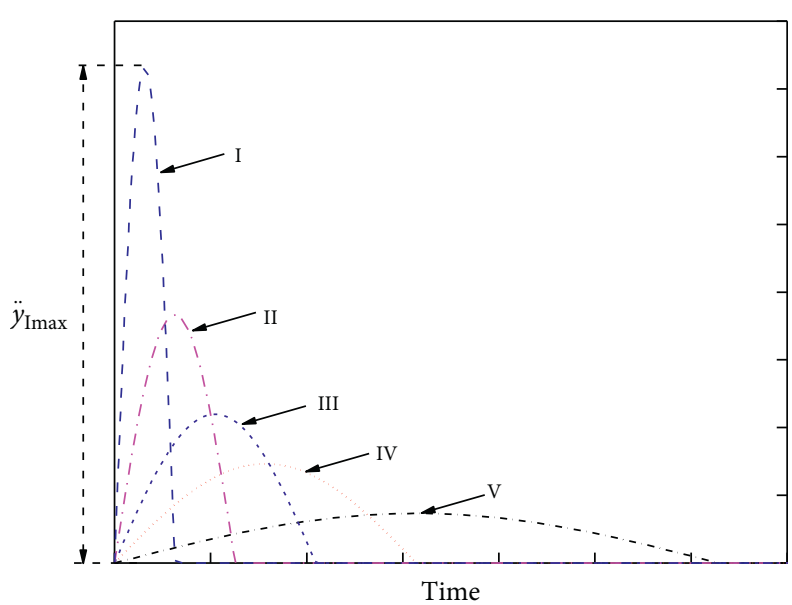

FIgURE 8: Shock loads of the isokinetic shock model.

$\left.\omega_{n} / g\right), \bar{\delta}=\left(\delta \omega_{n}^{2} / g\right), \quad \gamma=\left(k_{\delta 2} g^{2} / m_{1} \omega_{n}^{6}\right), \quad \Omega=\left(\omega_{0} / \omega_{n}\right), \quad \ddot{\bar{Y}}=$ $\left(-\ddot{y}_{\max } / g\right), C^{\prime}=\int_{0}^{(\pi / \Omega)} \ddot{\bar{Y}} \sin (\Omega \tau) \mathrm{d} \tau$, where $g$ is the constant of gravitational acceleration. Equation (14) can be rewritten as follows:

$$
\ddot{\bar{\delta}}+\varepsilon \dot{\bar{\delta}}+\bar{\delta}+\gamma \bar{\delta}^{3}=\left\{\ddot{\bar{Y}} \sin (\Omega \tau), 0<\tau \leq \frac{\pi}{\Omega}, 0, \tau>\frac{\pi}{\Omega} .\right.
$$

From equation (15), it can be seen that the shock response $\bar{\delta}$ mainly depends on the dimensionless damping coefficient $\varepsilon$, the dimensionless nonlinear stiffness coefficient $\gamma$, and the dimensionless velocity constant $C^{\prime}$ of the system. The dimensionless velocity constant $C^{\prime}$ is dẹtermined by the dimensionless shock excitation peak value $\bar{Y}$ and the ratio $\Omega$ of the angular frequency of shock excitation to the linear angular frequency of the shock isolation system.

To investigate the effects of damping coefficient on shock distinguishing, the dimensionless nonlinear stiffness coefficient $\gamma$ and the dimensionless velocity constant $C^{\prime}$ are set as 0 and 6.66, respectively. Figure 9 shows the ratio of the maximum relative displacement response to the ratio of the angular frequency $\Omega$.

In Figure 9, the ordinate represents the relative displacement ratio (RDR), defined as the ratio of the maximum value of the absolute value of the relative displacement response under the isokinetic shock load of $\Omega=i$ to the maximum value of the absolute value of the relative displacement response under the isokinetic shock load of $\Omega=1$ (i.e., RDR). It can be seen that when the value of $\Omega$ increases, the curve can be roughly divided into three states. When $\Omega$ approaches 0 , the RDR of this system also approaches 0 . This is because, when the value of $\Omega$ is small, the duration time $\tau$ of isokinetic shock excitation is much longer than the linear natural period of the shock isolation system. At this time, isokinetic shock excitation is more similar to the static loading process. The base $m_{2}$ is pushed up with a small acceleration increment, and the elastic force provided by the elastic element in the system is almost unchanged. That is, the spring length is almost unchanged, and the isolated object $m_{1}$ only makes small free vibrations in the equilibrium position. The damping force will increase the relative acceleration between the base and the isolated object. Therefore, the larger the damping ratio $\varepsilon$, the more violent the vibration of the isolated object $m_{1}$ and the greater the amplitude. When the value of $\Omega$ continues to increase, the system enters the transition stage of static loading and shock state. This stage is more similar to the forced vibration of the system under isokinetic shock loads and also to the free attenuation vibration of the system under damping. Its remarkable feature is that the RDR increases rapidly and that the damping has almost little effect on the RDR of the system. When the value of $\Omega$ is greater than or equal to 5 , the RDR of the system is stable to that caused by equivalent step velocity load (ESVL). At this time, considerate 


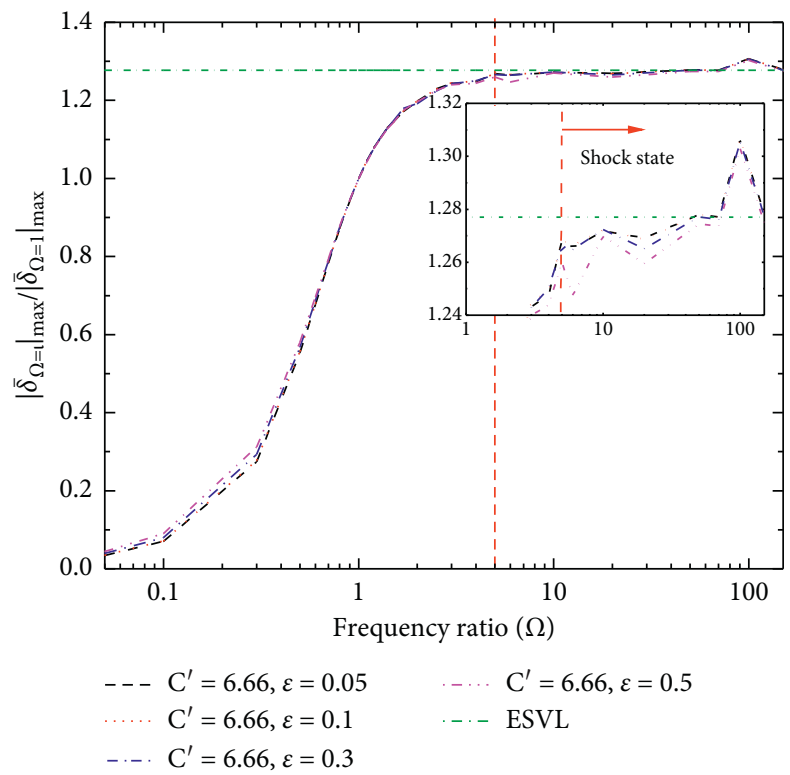

Figure 9: The effects of damping coefficient $\varepsilon$ on shock distinguishing.

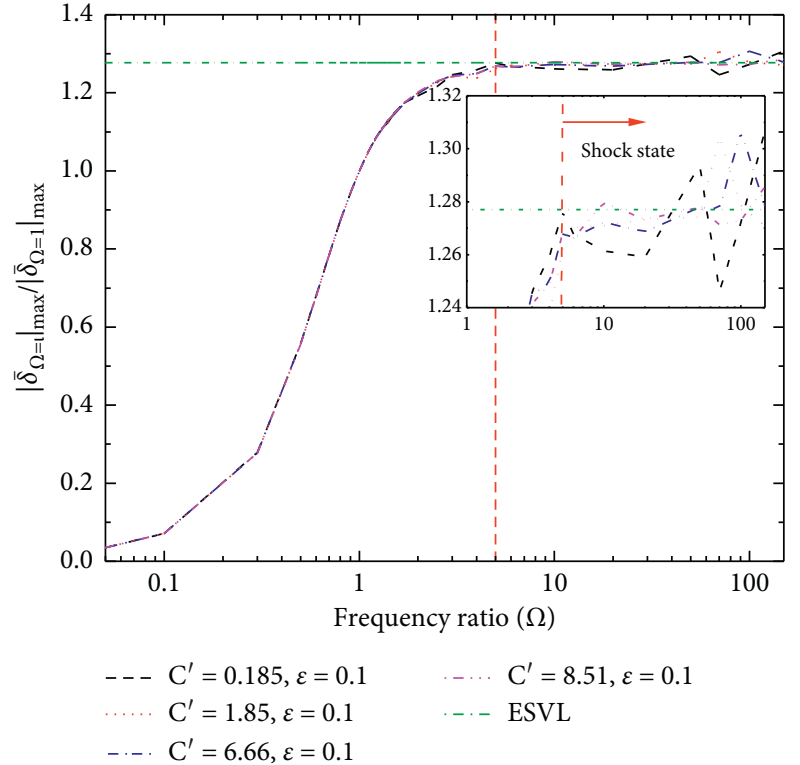

(a)

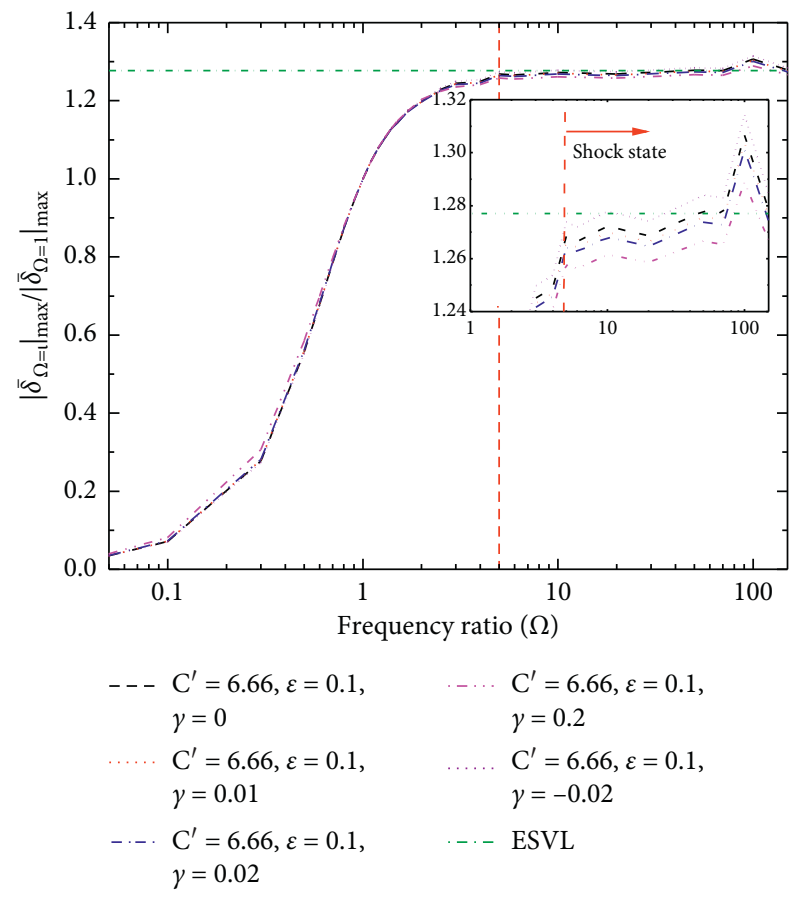

(b)

FIGURE 10: The effects of the system parameter on shock distinguishing. (a) Changing the dimensionless velocity constant $C^{\prime}$ of the system. (b) Changing the dimensionless nonlinear stiffness coefficient $\gamma$ of the system.

can be concluded that when the value of $\Omega$ is greater than or equal to 5 , there is little difference between the system response and the response caused by ideal impulse excitation. The shock isolation system enters the shock state, in which case the larger the damping ratio $\varepsilon$, the smaller the RDR under the same condition.

To investigate the effects of the dimensionless velocity constant $C^{\prime}$ on shock distinguishing, the dimensionless nonlinear stiffness coefficient $\gamma$ and the dimensionless damping coefficient $\varepsilon$ are set as 0 and 0.1 , respectively. Figure 10(a) shows the effects of the dimensionless velocity constant $C^{\prime}$ on the system. Similarly, to clarify the effects of the dimensionless nonlinear stiffness coefficient $\gamma$ on shock distinguishing, the dimensionless velocity constant $C^{\prime}$ and the dimensionless damping coefficient $\varepsilon$ are set as 6.66 and 0.1 , respectively. The dimensionless stiffness $\gamma$ endows the system with different characteristics. When $\gamma=0$, the system is linear stiffness, when $\gamma>0$, the system is "gradually hard" stiffness, and when $\gamma<0$, 
the system is "gradually soft" stiffness. Figure 10(b) shows the effects of the dimensionless stiffness $\gamma$ on the system. It can be seen from Figures 10(a) and 10(b) that the distinguishing of the shock state by different dimensionless velocity constant $C^{\prime}$ and the dimensionless stiffness $\gamma$ uniformly appears around $\Omega=5$. The influence of the dimensionless velocity constant $C^{\prime}$ on the system is mainly reflected in the shock state, where $\Omega$ is greater than 5. Compared with that caused by a larger $C^{\prime}$ value, the response caused by a smaller $C^{\prime}$ value makes the system similar to the equivalent step velocity load (ESVL), but its RDR fluctuates more significantly. The above shows that the higher the instantaneous energy received by the system, the more obvious the shock state. This can also be explained by the theory of momentum theorem [28]. For the dimensionless nonlinear stiffness coefficient $\gamma$, the change of stiffness characteristics will only change the response value, but not the state reflected by the system. In conclusion, the state of the system is only related to the frequency ratio $\Omega$.

\section{Dynamic Model and Simulation Analysis of the ODS Shock Isolator}

4.1. Shock Dynamic Model of the ODS Shock Isolator. It can be seen from the analysis in Section 2.2 that the boundary friction provides additional $F_{\mu i}$ for the system and that the direction of the additional support $F_{\mu i}$ is opposite to the velocity direction of the system. So, the sign function can be used to describe the additional support $F_{\mu i}$. The base excitation shock model of the ODS shock isolator with variable stiffness is established, as shown by the schematic diagram in Figure 11 .

$x_{0}$ is the displacement change of the balance position of the system after static load is applied. On the basis of introducing the total displacement of the system $\chi=x+x_{0}$, the motion differential equation of the ODS shock isolator under the base excitation can be expressed as follows according to equation (12):

$$
\begin{gathered}
m_{1} \ddot{\chi}+c(\dot{\chi}-\dot{y})+\sum_{i=1}^{n} F_{\mu i} \operatorname{sgn}(\dot{\chi}-\dot{y})+\left[K_{1}(\chi-y)+K_{2}(\chi-y)^{2}+K_{3}(\chi-y)^{3}+\beta\right]=m_{1} g, \\
\operatorname{sgn}(\dot{\chi}-\dot{y})= \begin{cases}1, & (\dot{\chi}-\dot{y})>0, \\
0, & (\dot{\chi}-\dot{y})=0, \\
-1, & (\dot{\chi}-\dot{y})<0 .\end{cases}
\end{gathered}
$$

Assuming $\lambda=x-y$, it can be substituted into equations (16) and (17) to obtain equations (18) and (19) through simplification:

$$
\begin{aligned}
& m_{1} \ddot{\lambda}+c \dot{\lambda}+\sum_{i=1}^{n} F_{\mu i} \operatorname{sgn} \dot{\lambda}+\left(K_{1}+2 K_{2} x_{0}+3 K_{3} x_{0}^{2}\right) \lambda+\left(K_{2}+K_{3} x_{0}^{2}\right) \lambda^{2}+K_{3} \lambda^{3}=-m_{1} \ddot{y} \\
& \ddot{y}=\left\{\ddot{y}_{\max } \sin \left(\omega_{0} T\right), 0 \leq T<\frac{\pi}{\omega_{0}}, 0, T \geq \frac{\pi}{\omega_{0}} .\right. \\
& \ddot{\bar{\delta}}+\varepsilon \dot{\bar{\delta}}+\varepsilon-\bar{\delta} \operatorname{sgn}(\dot{\bar{\delta}})+\bar{\delta}+\gamma_{1} \bar{\delta}^{2}+\gamma \bar{\delta}^{3}=0, \\
& \bar{\delta}(0)=0 ; \\
& \dot{\bar{\delta}}(0)=C^{\prime}=\int_{0}^{(\pi / \Omega)} \ddot{\bar{Y}} \sin (\Omega \tau) \mathrm{d} \tau .
\end{aligned}
$$

After introducing the linear angular frequency of the ODS shock isolator $\omega_{n}^{2}=\left(\left(K_{1}+2 x_{0} K_{2}+3 x_{0}^{2} K_{3}\right) / m_{1}\right)$ and the dimensionless parameters $\tau=\omega_{n} T, . . \Omega=\left(\omega_{0} / \omega_{n}\right)$, $\bar{\delta}=(\ddot{\lambda} / g), \quad \bar{\delta}=(\dot{\lambda} / g) \omega_{n}, \quad \bar{\delta}=(\lambda / g) \omega_{n}^{2}, \quad \bar{Y}=\left(-\ddot{y}_{\max } / g\right)$, $\varepsilon=\left(c / m_{1} \omega_{n}\right), \gamma_{1}=\left(g\left(K_{2}+3 K_{3} x_{0}^{2}\right) / m_{1} \omega_{n}^{4}\right), \gamma=\left(g^{2} K_{3} / m_{1}\right.$ $\left.\omega_{n}^{6}\right)$, and $\varepsilon_{\bar{\delta}}=\left(\sum_{i=1}^{n} F_{\mu i} / m_{1} \omega_{n}\right)$, equations (18) and (19) can be nondimensionalized to obtain equations (20) and (21).

$$
\begin{gathered}
\ddot{\bar{\delta}}+\varepsilon \dot{\bar{\delta}}+\varepsilon_{\bar{\delta}} \operatorname{sgn}(\dot{\bar{\delta}})+\bar{\delta}+\gamma_{1} \bar{\delta}^{2}+\gamma \bar{\delta}^{3}=\bar{F}, \\
\bar{F}=\left\{\ddot{\bar{Y}} \sin (\Omega \tau), 0<\tau \leq \frac{\pi}{\Omega}, 0, \tau>\frac{\pi}{\Omega} .\right.
\end{gathered}
$$

It can be seen from Section 3 that when $\Omega>5$, the system enters the shock state, and its response is approximately equivalent to a free vibration system with initial velocity. That is, equations (20) and (21) are equivalent to
Relying on the idea of the average method, the solution of equation (22) is as follows:

$$
\begin{aligned}
\ddot{\bar{\delta}}+\bar{\delta} & =\xi f(\bar{\delta}, \dot{\bar{\delta}}) \\
f(\bar{\delta}, \dot{\bar{\delta}}) & =\frac{1}{\xi}\left(\varepsilon \dot{\bar{\delta}}+\varepsilon \bar{\delta} \operatorname{sgn}(\dot{\bar{\delta}})+\gamma_{1} \bar{\delta}^{2}+\gamma \bar{\delta}^{3}\right) .
\end{aligned}
$$

The forms of the solution of equation $\bar{\delta}=a \cdot \cos (\psi)$ and $\psi=\tau+\theta$, can be introduced: 


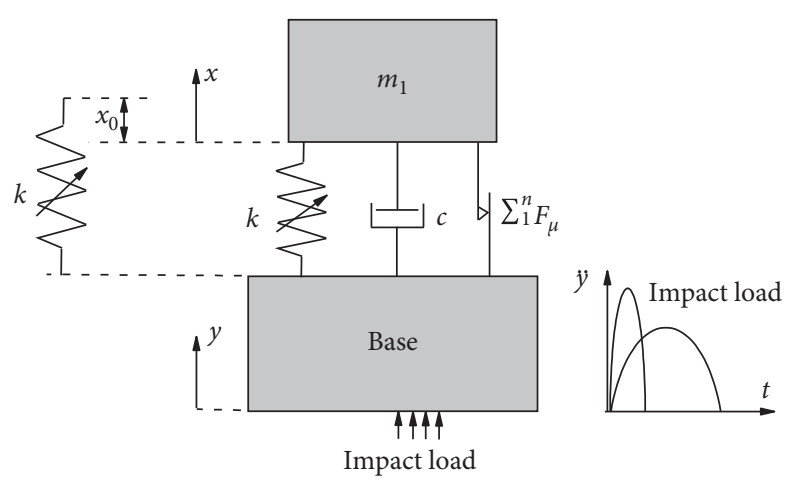

FIGURE 11: Model of the disc spring-mass system with variable stiffness under base excitation shock.

$$
\begin{aligned}
\frac{\mathrm{d} a}{\mathrm{~d} \tau} & =-\frac{\xi}{2 \pi} \int_{0}^{2 \pi} f(a \cos \psi,-a \sin \psi) \sin \psi \mathrm{d} \psi \\
& =-\frac{\xi}{2 \pi} \frac{1}{\xi} \int_{0}^{2 \pi}\left[\varepsilon a \sin \psi+\varepsilon_{\bar{\delta}} \operatorname{sgn}(\sin \psi)-\gamma_{1} a^{2} \cos ^{2} \psi-\gamma a^{3} \cos ^{3} \psi\right] \sin \psi \mathrm{d} \psi \\
& =-\left(\frac{\varepsilon}{2} a+\frac{2 \varepsilon_{\bar{\delta}}}{\pi}\right), \\
\frac{\mathrm{d} \theta}{\mathrm{d} \tau} & =-\frac{\xi}{2 \pi a} \int_{0}^{2 \pi} f(a \cos \psi,-a \sin \psi) \cos \psi \mathrm{d} \psi \\
& =-\frac{\xi}{2 \pi} \frac{1}{\xi} \int_{0}^{2 \pi}\left(\varepsilon a \sin \psi+\varepsilon_{\bar{\delta}} \operatorname{sgn}(\sin \psi)-\gamma_{1} a^{2} \cos ^{2} \psi-\gamma a^{3} \cos ^{3} \psi\right) \cos \psi \mathrm{d} \psi \\
& =\frac{3 \gamma}{8} a^{2} .
\end{aligned}
$$

Thus, the solution of the first-order differential equation can be obtained and substituted into the forms of the solution. The vibration equation of the ODS shock isolator with initial velocity can be obtained:

$$
\bar{\delta}=\left[\left(a_{0}+\frac{4 \varepsilon_{\bar{\delta}}}{\pi \varepsilon}\right) e^{-(\varepsilon / 2) \tau}-\frac{4 \varepsilon_{\bar{\delta}}}{\pi \varepsilon}\right] \cos \left[\left(\frac{3 \gamma}{8} a^{2}+1\right) \tau+\theta_{0}\right],
$$

where the values of $a_{0}$ and $\theta_{0}$ are determined by the initial conditions $\bar{\delta}(0)$ and $\bar{\delta}(0)$ of the system. It can be seen from equation (25) that the shock response of the nonlinear system is related to the first-order and third-order coefficient of the stiffness, the bearing mass $\mathrm{m} 1$, the magnitude of the initial velocity, the viscous damping of the system, and the additional support force. To evaluate the shock isolation performance of the ODS shock isolator under the base excitation, a Matlab program based on the fourth-order Runge-Kutta algorithm is established to simulate the shock isolation response of the ODS shock isolator.

4.2. Effect of the Number of Disc Spring and Pretightening Force on Shock Response. It can be seen from Section 2.2 that the number of disc springs $n$ and the pretightening force
$F_{c}$ not only affect the stiffness characteristics of the system but also influence the sum of the additional supporting force $\sum_{i=1}^{n} F_{\mu i}$ of the system and the value of the linear angular frequency $\omega_{n}$. However, these two parameters are important in the calculation of shock response. So, it is necessary to analyze the effects of the number of disc springs and pretightening force on the additional support force.

According to equations (10) and (12) and the data in Tables 1 and 2, the curve of the sum of the additional supporting force-axial displacement of the system under the same number of disc springs and different pretightening forces can be calculated as shown in Figure 12(a). The curve of the sum of the additional supporting force-axial displacement of the system under different numbers of disc springs and same pretightening force can be calculated as shown in Figure 12(b).

The thickness $t$ and the friction coefficient $\mu_{e}$ of these disc springs are $0.5 \mathrm{~mm}$ and 0.2 , respectively. As shown in Figure 12(a), under the same number of disc springs and different pretightening forces, although the sum of the additional support force-axial displacement curves varies, the equivalent average of additional support forces $\bar{F}_{\mu}$ remains almost constant, with a value of about $60 \mathrm{~N}$. Additionally, under different numbers of disc springs and the same pretightening force, with the increase of the number of 


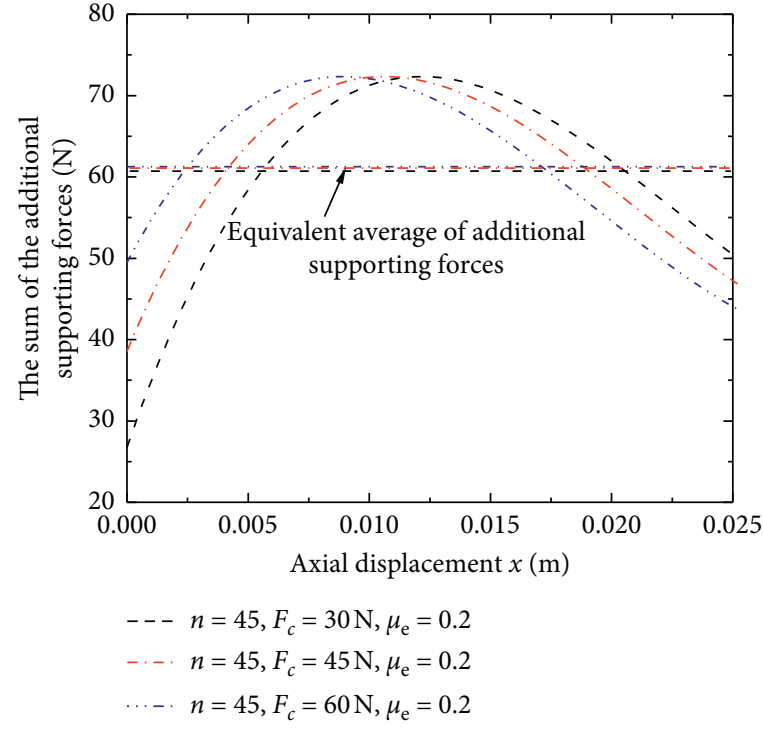

(a)

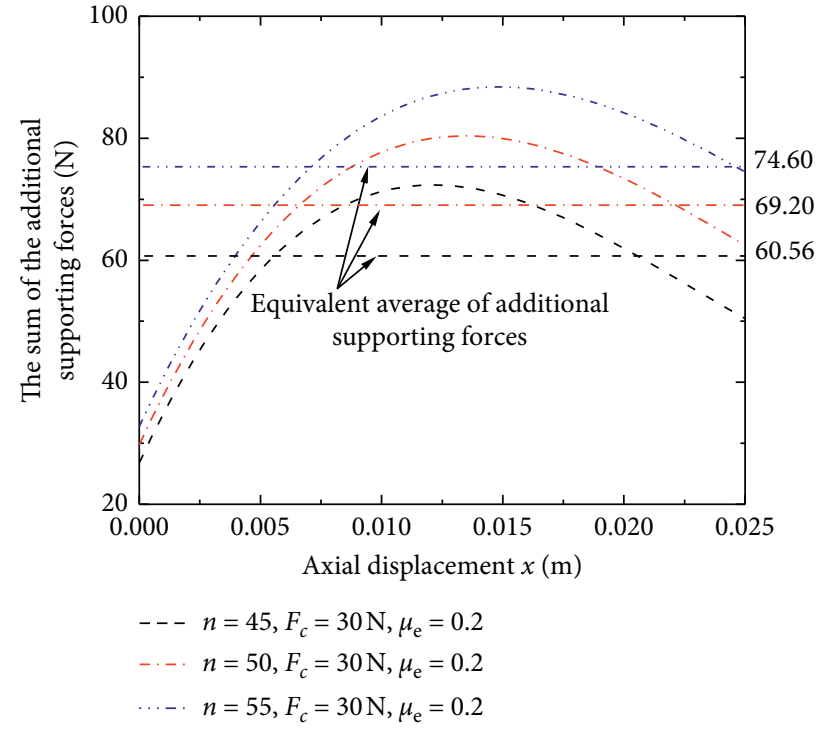

(b)

FIGURE 12: The sum of the additional supporting forces and axial displacement curve of the system. (a) The same number of disc springs and different pretightening forces and (b) different numbers of disc springs and the same pretightening force.

disc springs, the equivalent average of additional support forces $\bar{F}_{\mu}$ also increases. These rules still apply when the thickness of disc springs $t$ and the friction coefficient $\mu_{e}$ of the system are changed. Therefore, to simplify the model, the equivalent average of additional support forces $\bar{F}_{\mu}$ is applied to the system and introduced into the calculation, that is, the dimensionless parameter $\mathcal{E}_{\bar{\delta}}$ is a fixed value that does not vary with axial displacement and that is only related to the number of disc springs $n$.

Therefore, the calculation parameters of the ODS shock isolator are as follows. The thickness $t$ of the disc springs is $0.5 \mathrm{~mm}$, the friction coefficient $\mu_{e}$ is 0.2 , the linear viscous damping coefficient $c$ is 2 , and the system load $m 1$ is $4.46 \mathrm{Kg}$. The shock input is the shock loads of the isokinetic shock introduced in Section 3, and the dimensionless velocity constant $C^{\prime}$ is set as 5.55. The equivalent average of additional support forces with different numbers of disc springs in the system are specified in Table 3.

To evaluate the shock isolation performance of the ODS shock isolator, shock acceleration ratio (SAR), shock displacement ratio (SDR), and $\mathrm{RDR}$ are used $[23,29,30]$.

$$
\begin{aligned}
\mathrm{SAR} & =\frac{|\ddot{x}|_{\text {max }}}{|\ddot{y}|_{\text {max }}}=\frac{|\ddot{\bar{\delta}}+\bar{F}|_{\text {max }}}{|\bar{F}|_{\text {max }}}, \\
\mathrm{SDR} & =\frac{|x|_{\max }}{|y|_{\max }}=\frac{\left|\bar{\delta}+\iint(\bar{F} d \tau) \mathrm{d} \tau\right|_{\max }}{\left|\iint(\bar{F} d \tau) \mathrm{d} \tau\right|_{\max }}, \\
\mathrm{RDR} & =\frac{|x-y|_{\max }}{|y|_{\max }}=\frac{|\bar{\delta}|_{\max }}{\left|\iint(\bar{F} d \tau) \mathrm{d} \tau\right|_{\max }} .
\end{aligned}
$$

Figures 13(a) and 13(c) show the SAR, SDR, and RDR spectra of the ODS shock isolation system under a dimensionless velocity constant $C^{\prime}$ of 5.55 . When $\Omega$ approaches 0 , the system shows a quasistatic loading state. At this time, there is almost no deformation of the elastic element in the system, and the dimensionless relative displacement $\bar{\delta}$ is negligible relative to the absolute displacement of the base. So, $\mathrm{SDR} \approx \mathrm{RDR}+1$ and $\mathrm{SAR} \approx 1$ are established in the system, and this system has no isolation effect. With the gradual increase of $\Omega$ to around 1 , the system enters the transition state of forced vibration, and the duration of shock excitation is close to half of the natural period of the system. This causes resonance of the system, and the value of SAR is obviously greater than 1 . The isolation system is in the isolation amplification area. It can be clearly observed in this area that the ODS shock isolator with a large number of disc springs $n$ and large pretightening force has significantly smaller magnification in the SAR and SDR spectra than those with a small number of disc springs $n$ and small pretightening force. According to Section 3, when $\Omega>5$, the system enters the shock state. At this time, it can be seen that with the increase of $\Omega$, the SAR values of different ODS shock isolators are smaller. In addition, the ODS shock isolator with less disc springs and smaller pretightening force has slight advantage in displacement isolation compared with those with a large number of disc springs and large pretightening force. The values of RDR and SDR increase with the increase of $\Omega$, and the relationship between $\mathrm{RDR}$ and $\mathrm{SDR}$ is $\mathrm{RDR} \approx \mathrm{SDR}+1$. This shows that when the ODS shock isolator system enters the shock state, under the isokinetic shock, with the increase of the frequency ratio $\Omega$, the ability of the ODS shock isolator to isolate the shock acceleration becomes stronger, but the ability of the ODS shock isolator to isolate the displacement weakened. And with the increase of the frequency ratio $\Omega$, the influence of the number of disc springs and pretightening force on the isolation efficiency of the ODS shock 
TABLE 3: Fitting coefficient of elastic force and axial displacement of the shock isolator.

\begin{tabular}{ll}
\hline The number of disc springs, $n$ & $\bar{F}_{\mu}$ \\
\hline 45 & 60 \\
50 & 70 \\
55 & 75 \\
\hline
\end{tabular}
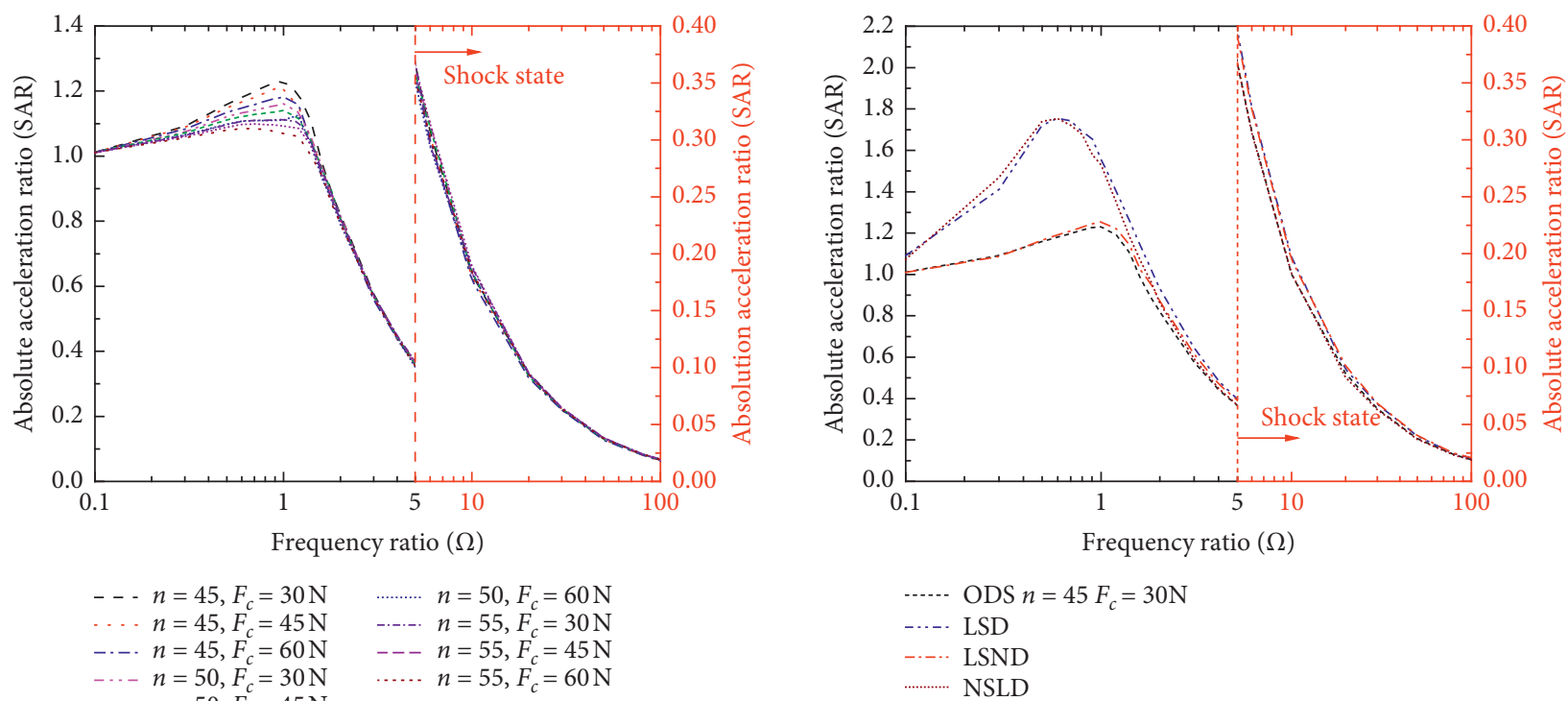

(a)

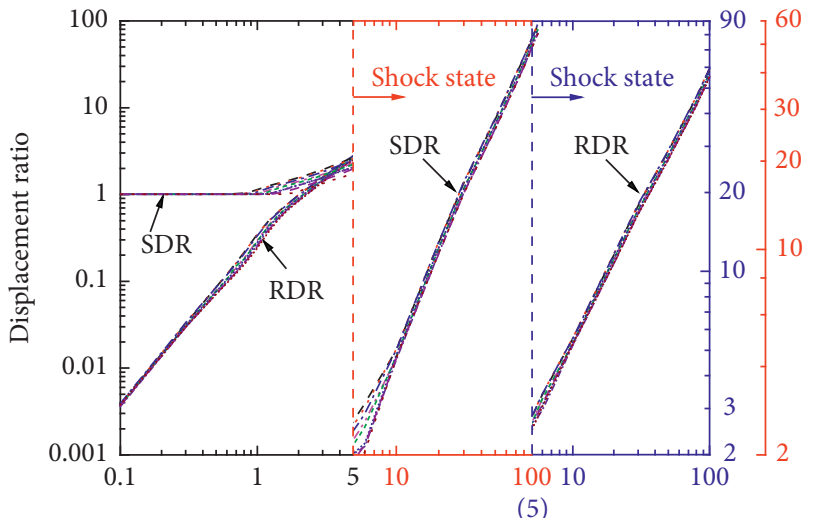

Frequency ratio $(\Omega)$ (c)

$$
\begin{aligned}
& n=50, F_{c}=60 \mathrm{~N} \\
& \text { … } n=55, F_{c}=30 \mathrm{~N} \\
& --n=55, F_{c}=45 \mathrm{~N} \\
& \text { …n } n=55, F_{c}=60 \mathrm{~N}
\end{aligned}
$$

(b)

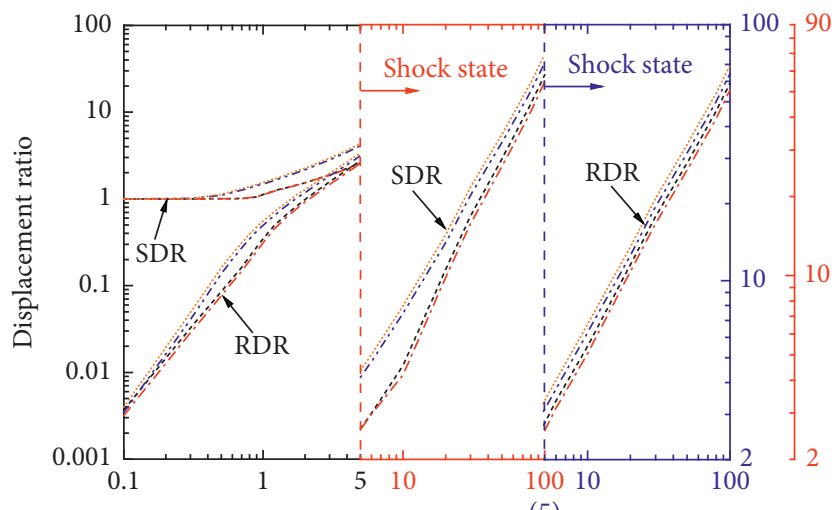

(5)

Frequency ratio $(\Omega)$

(d)

FIGURE 13: The SAR, SDR, and RDR spectra of the ODS shock isolator system of isokinetic shock load with different numbers of the disc springs and pretightening forces. (a) SAR spectra of the ODS shock isolator system. (b) SAR spectra of the ODS shock isolator system and linear and nonlinear shock isolation systems under the same parameters. (c) SDR and RDR spectra of the ODS shock isolator system. (d) SDR and RDR spectra of the ODS shock isolator system and linear and nonlinear shock isolation systems under the same parameters (LSD represents the linear stiffness and linear damping shock isolation system with the same corresponding parameter terms as the ODS shock isolator. LSND represents the linear stiffness and nonlinear damping shock isolation system with the same corresponding parameter terms as the ODS shock isolator. NSLD represents the nonlinear stiffness and linear damping shock isolation system with the same corresponding parameter terms as the ODS shock isolator). 
isolator is also weaker. Figures $13(\mathrm{~b})$ and $13(\mathrm{~d})$ show the SAR, RDR, and SDR spectra of the ODS shock isolator and different shock isolation systems under the same corresponding parameter terms and a dimensionless velocity constant $C^{\prime}$ of 5.55. Comparison reveals that the ODS shock isolator has certain advantages in isolating shock loads. Although the shock isolation performance of the ODS shock isolator is slightly weaker than that of the NSLD shock isolation system in the shock state with $\Omega>5$, the isolation performance of the ODS shock isolator is obviously better than that of the NSLD shock isolation system in the transition state with $\Omega \leq 5$. This reflects the excellent isolation characteristics of the ODS isolator within the whole frequency domain.

4.3. Effect of the Payload on Shock Response. The bearing mass $m_{1}$ of the ODS shock isolator system not only affects the dimension parameters but also influences the static loaddisplacement compression $x_{0}$. From the initial bearing capacity $F_{r}$ of equation (9), it can be known that when the gravity of the bearing mass $m_{1} g \leq F_{r}$, the static load-displacement compression $x_{0}$ is zero. But when the gravity of the bearing mass $m_{1} g>F_{r}$, the static load-displacement compression $x_{0}$ should approximately conform to the following equation:

$$
m_{1} g=K_{1} x_{0}+K_{2} x_{0}^{2}+K_{3} x_{0}^{3}+\beta+\bar{F}_{\mu} .
$$

Therefore, to investigate the effect of different bearing masses on the ODS shock isolator system, when $m_{1} g \leq F_{r}$, the bearing masses $m_{1}$ are set as $2.46 \mathrm{Kg}, 3.46 \mathrm{Kg}$, and $4.46 \mathrm{Kg}$, respectively. Similarly, when $m_{1} g>F_{r}$, the bearing masses $m_{1}$ are set as $11.46 \mathrm{Kg}, 12.46 \mathrm{Kg}$, and $13.46 \mathrm{Kg}$. Figures 14(a) and 14(c) show the SAR, SDR, and RDR spectra of the ODS shock isolator system with different bearing masses under the loads of the isokinetic shock, where the thickness $t$ and the number $n$ of the disc springs are, respectively, $0.5 \mathrm{~mm}$ and 45 , and the value of $\bar{F}_{\mu}$ is $60 \mathrm{~N}$, as given in Table 3, the pretightening force $F_{c}$ is $45 \mathrm{~N}$, the friction coefficient $\mu_{e}$ is 0.2 , the linear viscous damping coefficient $c$ is 2 , and the dimensionless velocity constant $C^{\prime}$ is 5.55 .

Figures 14(a) and 14(c) show that when $m_{1} g \leq F_{r}$ in the ODS shock isolator system, for the forced vibration transition area and quasistatic loading area with $\Omega<5$, the absolute acceleration, relative displacement, and absolute displacement magnification of the system with small bearing mass are smaller, but the resonance frequency will move to the high frequency direction. In the shock state of $\Omega>5$, the bearing mass only exerts weak effects on SAR, SDR, and RDR. The system with large bearing mass has a little advantage in isolation of absolute acceleration, but it is slightly worse than the system with small bearing mass in isolation of relative and absolute displacement. When $m_{1} g>F_{r}$, within the whole frequency domain, the isolation effect of the ODS shock isolator system with large bearing mass is better than that of the system with small bearing mass. For displacement isolation, the ODS shock isolator system with large bearing mass is significantly worse than the system with small bearing mass. Moreover, large bearing mass will lead to large static load-displacement compression $x_{0}$, which is inconducive to the shock isolation of the large dimensionless velocity constant $C^{\prime}$ and easy to cause secondary shock. In addition, it is found that when the system enters the shock state and $\Omega>10$, for any value of $m_{1}$, the relationship between $\mathrm{RDR}$ and $\mathrm{SDR}$ is $\mathrm{RDR} \approx \mathrm{SDR}+1$. Figures $14(\mathrm{~b})$ and 14(d) show the SAR, RDR, and SDR spectra of the ODS shock isolator, LSD shock isolator, LSND shock isolator, and NSLD shock isolator. The corresponding parameter terms of these four kinds of shock isolators are equal, and the dimensionless velocity constant $C^{\prime}$ is 5.55 . The bearing masses $m_{1}$ of these four shock isolation systems are set as $4.46 \mathrm{Kg}$ and $12.46 \mathrm{Kg}$. It can be found by comparison that the ODS shock isolator has more balanced isolation performance than the other three commonly used shock isolation systems with the change of $\Omega$ from zero to infinite, regardless of the load state.

\subsection{Effect of the Dimensionless Velocity Constant $C^{\prime}$ on Shock} Response. The dimensionless velocity constant $C^{\prime}$ represents the amount of input energy to the system. Although it has been fully verified in Section 3 that the dimensionless velocity constant $C^{\prime}$ has a little effect on the system in the shock state, after the system enters the shock state, the response caused by the small dimensionless velocity constant $C^{\prime}$ is still different from that caused by the large dimensionless velocity constant C'. Therefore, the shock responses of the ODS shock isolator system with different dimensionless velocity constants are calculated, and the SAR, SDR, and RDR spectra are compared. The calculation parameters of the system are as follows: the thickness $t$ and the number $n$ of the disc springs are $0.5 \mathrm{~mm}$ and 45 , the pretightening force $F_{c}$ is $45 \mathrm{~N}$, the friction coefficient $\mu_{e}$ is 0.2 , and the linear viscous damping coefficient $c$ is 2 , and the bearing mass $m_{1}$ is set as $4.46 \mathrm{Kg}$.

Figures 15(a) and 15(c) show the SAR, SDR, and RDR spectra of the ODS shock isolator system with a different dimensionless velocity constant $C$ '. It can be seen from Figure 15(a) that when the system is in the quasistatic load and forced vibration transition state $(\Omega<2)$, with the decrease of the dimensionless velocity constant $C^{\prime}$, the acceleration amplification ratio of the ODS shock isolator system decreases. However, when the ODS shock isolator system is in shock state, i.e. $\Omega>5$, the absolute acceleration isolation ability of the system with small dimensionless velocity constant is obviously weaker than those with large dimensionless velocity constant. Figure 15(c) shows that when the ODS shock isolator system is in shock state, the absolute displacement isolation ability of the system with small dimensionless velocity constant is better than those with large dimensionless velocity constant. When the frequency ratio $\Omega>10$, the relationship between the RDR and $\mathrm{SDR}$ is $\mathrm{RDR} \approx \mathrm{SDR}+1$ for any dimensionless velocity constant. Figures 15(b) and 15(d) also show the excellent isolation performance of the ODS shock isolator compared with common isolation systems within the whole frequency domain through SAR, SDR, and RDR spectra under different shock environments. 


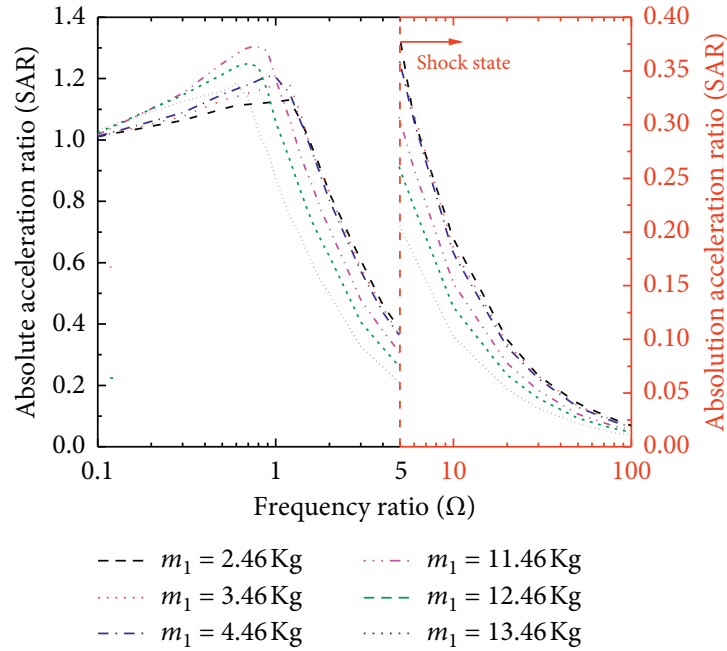

(a)

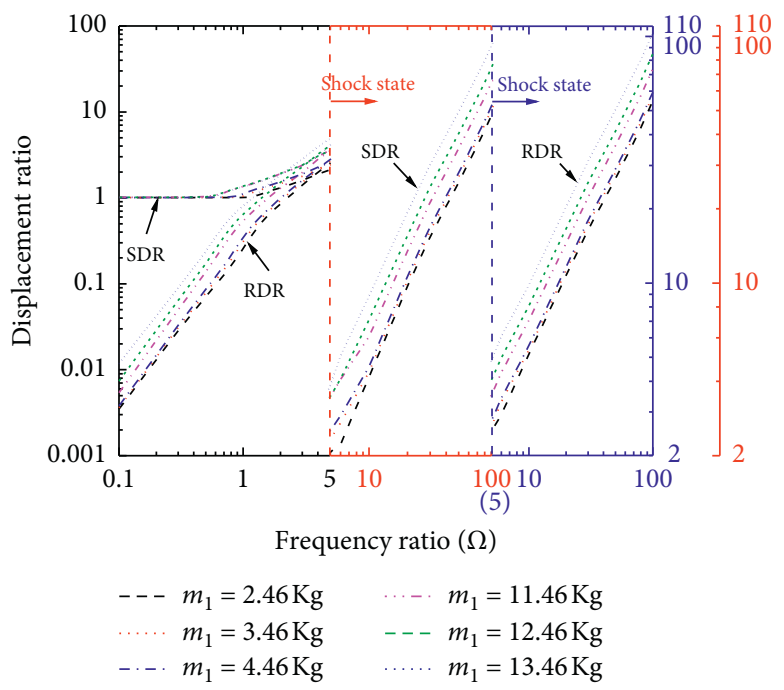

(c)

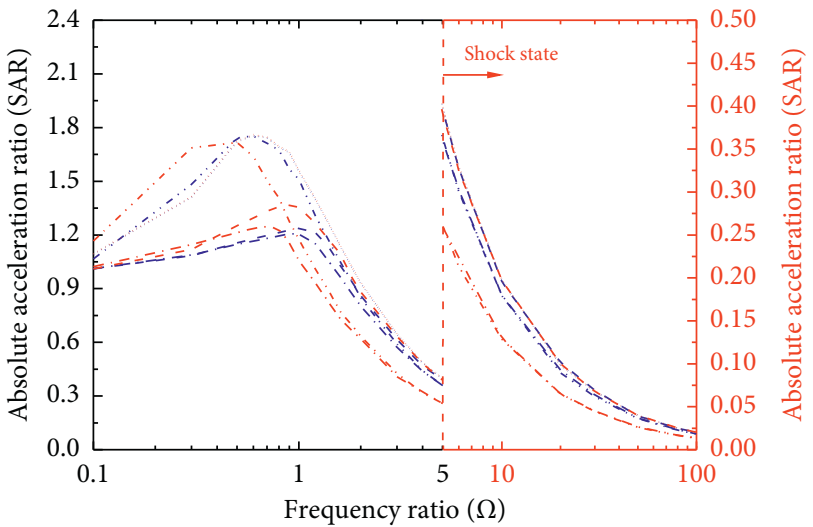

$$
\begin{aligned}
& \text {-. . ODS } m_{1}=4.46 \mathrm{Kg}, \quad-\ldots \quad \text { LSND } m_{1}=12.46 \mathrm{Kg} \\
& n=45, F_{c}=45 \mathrm{~N} \\
& \text { … LSD } m_{1}=4.46 \mathrm{Kg} \quad \ldots . . \quad \text { LSD } m_{1}=12.46 \mathrm{Kg} \\
& \text { - - } \quad \text { LSND } m_{1}=4.46 \mathrm{Kg} \mathrm{-...} \mathrm{ODS} m_{1}=12.46 \mathrm{Kg} \text {, } \\
& \begin{array}{lll}
\text { NSLD } m_{1}=4.46 \mathrm{Kg} \cdots . . & \text { NSLD } m_{1}=12.46 \mathrm{Kg}
\end{array}
\end{aligned}
$$

(b)

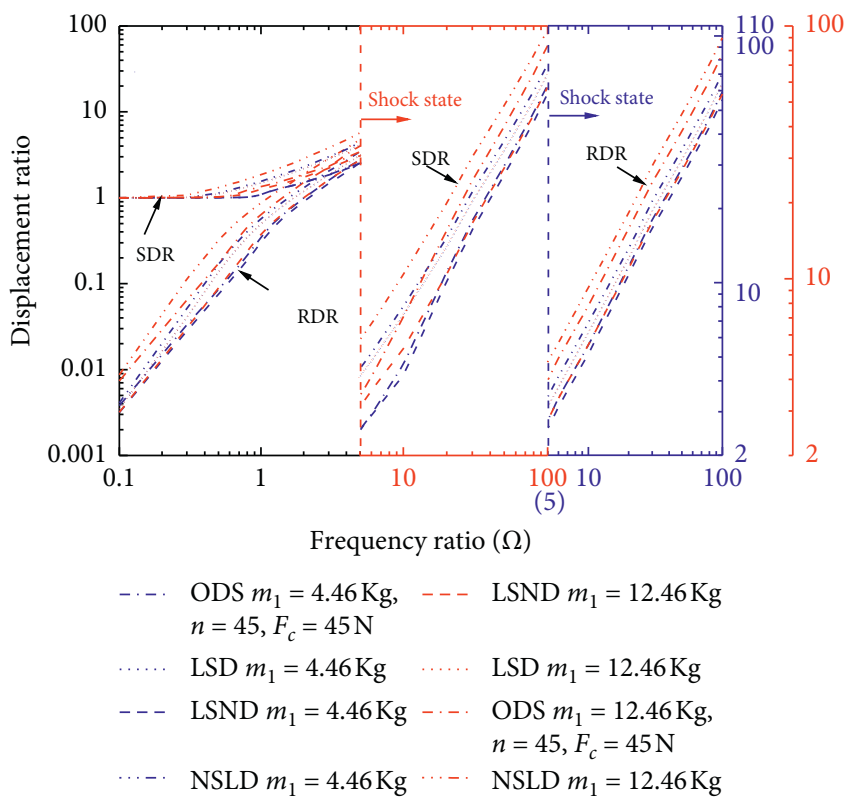

(d)

FIGURE 14: The SAR, SDR, and RDR spectra of the ODS shock isolator system of isokinetic shock load with different bearing masses. (a) SAR spectra of the ODS shock isolator system. (b) SAR spectra of the ODS shock isolator system and linear and nonlinear shock isolation systems under the same parameters. (c) SDR and RDR spectra of the ODS shock isolator system. (d) SDR and RDR spectra of the ODS shock isolator system and linear and nonlinear shock isolation systems under the same parameters.

\section{Shock Experiment and Result Discussion}

5.1. Experiment Setup. To investigate the accuracy of the isokinetic shock distinguishing method and the performance of the ODS shock isolator with boundary friction and pretightening, an ODS shock isolator is proposed. The parameters of the DOS shock isolator are as follows. The outer diameter $D$ and inner diameter $d$ of the disc springs are $28 \mathrm{~mm}$ and $10 \mathrm{~mm}$, the free height $H_{0}$ and the flattening height $h_{0}$ of the disc springs are $1.15 \mathrm{~mm}$ and $0.7 \mathrm{~mm}$, the thickness $t$ and the number of the disc springs $n$ are $0.5 \mathrm{~mm}$ and 45 , the pretightening is set as $45 \mathrm{~N}$, and the bearing mass $m_{1}$ of the ODS shock isolator system is $4.46 \mathrm{Kg}$. Silicone oil is filled into the pipe wall of the ODS shock isolator, and single-DOF isokinetic shock test is performed on the ODS shock isolator.

The experimental system (Figure 16(a)) is composed of three parts: a base excitation system, a data acquisition system, and an ODS shock isolation system. The base excitation system is the SY10-500 drop shock tester. The data acquisition system includes three piezoelectric-type acceleration sensors 


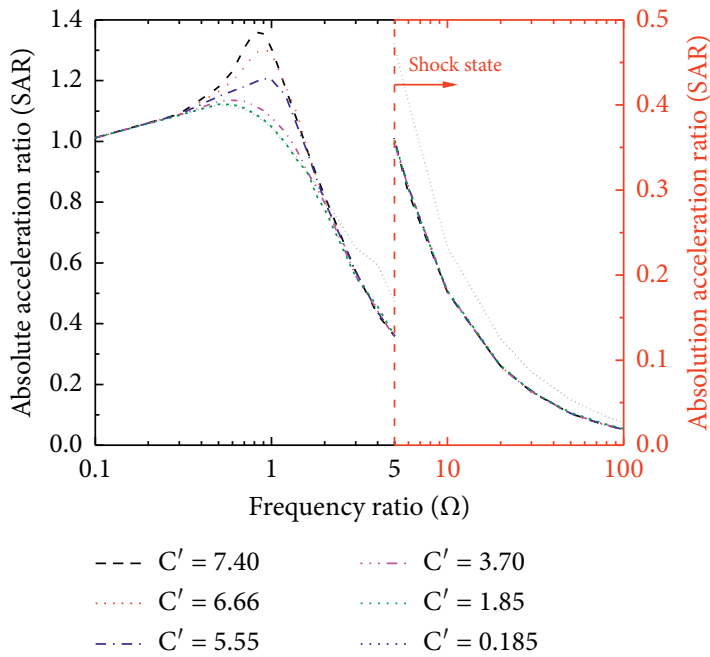

(a)

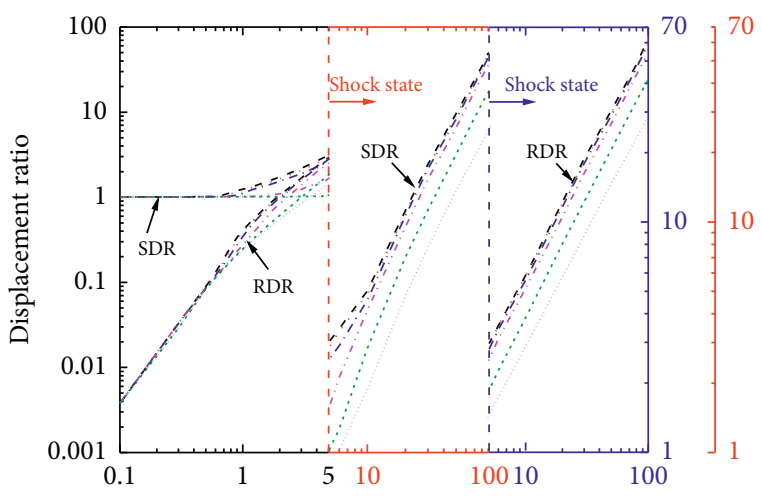

(5)

Frequency ratio $(\Omega)$

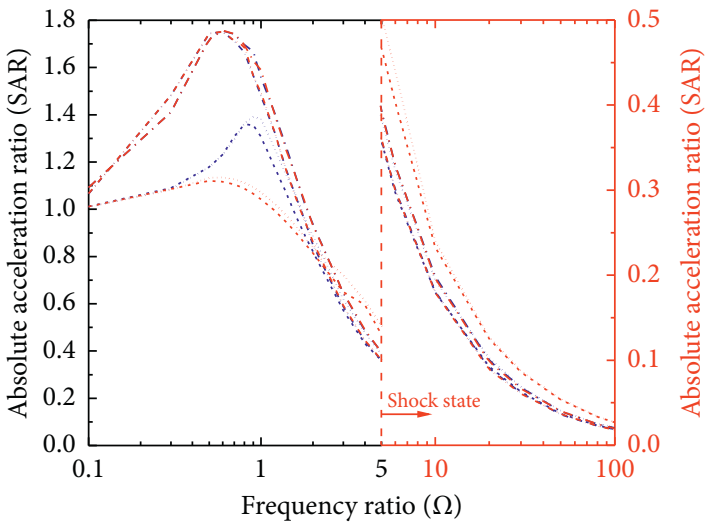

$$
\begin{aligned}
& \text { ODS } C^{\prime}=7.40 \quad \text { ODS } C^{\prime}=0.185
\end{aligned}
$$

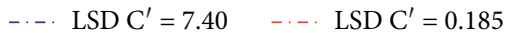

$$
\begin{aligned}
& \text { … } \text { LSND C }^{\prime}=7.40 \cdots . . \quad \text { LSND }^{\prime}=0.185 \\
& \text {-... } \text { NSLD C }^{\prime}=7.40 \ldots \text { NSLD C }^{\prime}=0.185
\end{aligned}
$$

(b)

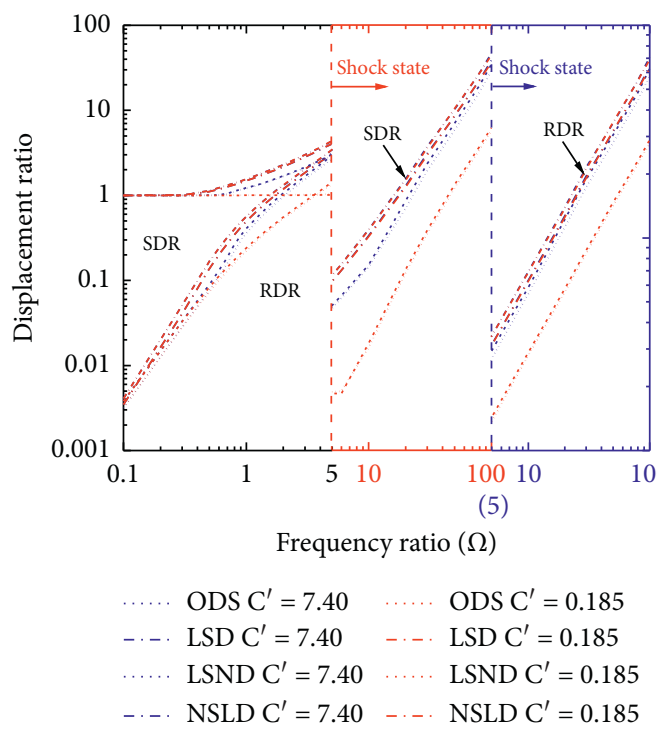

(d)

(c)

FIGURE 15: The SAR, SDR, and RDR spectra of the ODS shock isolator system of isokinetic shock load with different dimensionless velocity constant $C^{\prime}$. (a) SAR spectra of the ODS shock isolator system (b) SAR spectra of the ODS shock isolator system and linear and nonlinear shock isolation systems under the same corresponding parameter terms. (c) SDR and RDR spectra of the ODS shock isolator system. (d) SDR and RDR spectra of the ODS shock isolator system and linear and nonlinear shock isolation systems under the same corresponding parameter terms.

(model DL112), one rail-type magnetostrictive displacement sensor (model CMSD0180), one charge amplifier (model MI2004), one dynamic data analyzer (model MI-7008), and personal computers (PC). The shock responsive acceleration signals of the ODS shock isolator are collected with three acceleration sensors. Two of them are connected to the charge amplifier, and the acceleration signals of the base and mass can be acquired. The third is connected to the control system of the drop shock test as a monitoring signal of the base. The ODS shock isolation system (Figure 16(c)) consists of the ODS shock isolator, installation base, and load mass. The load mass consisted of a cylinder, a support plate, and two linear bearings. The ODS shock isolator is installed between load mass and the base. Two linear guides are fixed to the installation base to keep the vertically translational motion of the load mass.

5.2. Experiment Results and Discussion. To verify the accuracy of ISDM and the shock isolation performance of the ODS shock isolator with the base excitation which is isokinetic shock load in the simulation calculation, the dimensionless velocity constant $C^{\prime}=5.55$ (the actual table shock velocity is $1.2 \mathrm{~m} / \mathrm{s}$ ) and $C^{\prime}=7.40$ (the actual table shock velocity is $1.6 \mathrm{~m} / \mathrm{s}$ ) are set as isokinetic shock excitation, respectively, and a series of shock tests are carried out. 


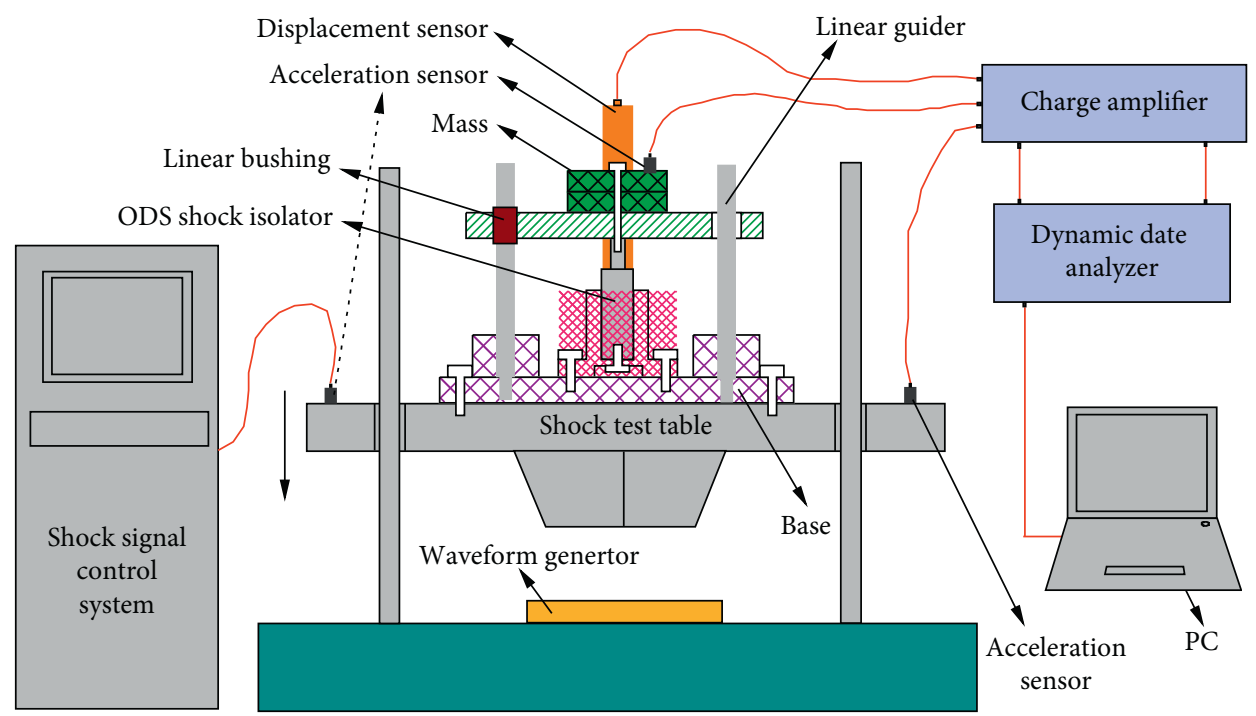

(a)

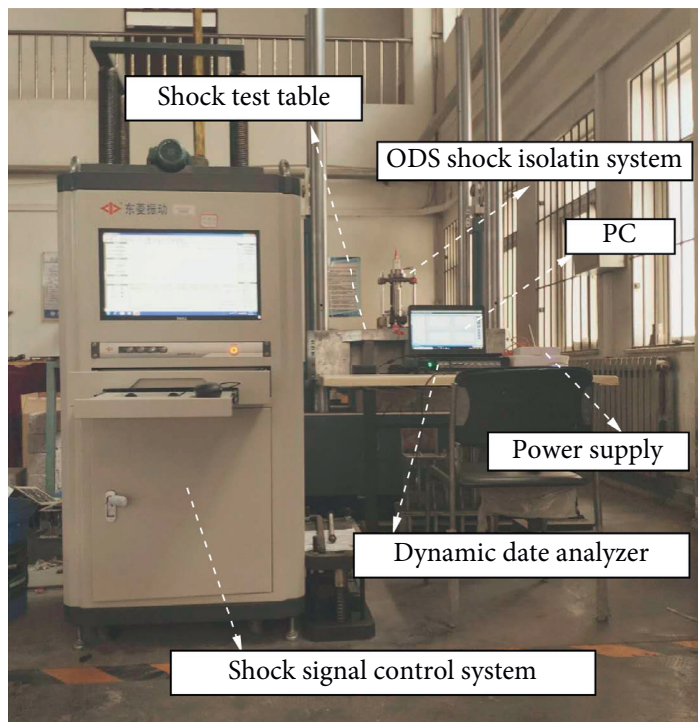

(b)

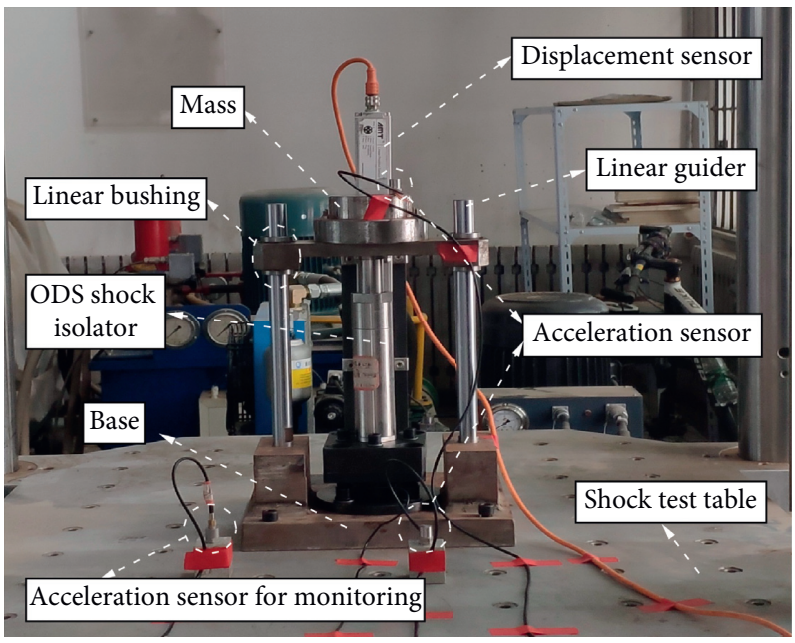

(c)

FIGURE 16: The ODS shock isolation experiment system. (a) Schematic diagram of the shock experiment system; (b) photograph of the shock experiment system; (c) photograph of the ODS shock isolation system. 


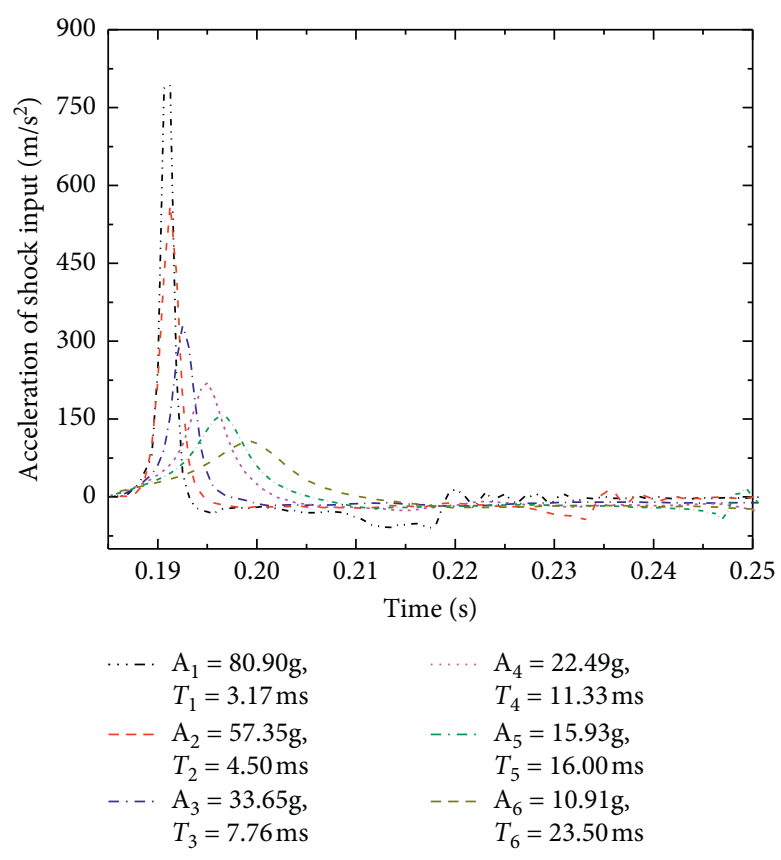

(a)

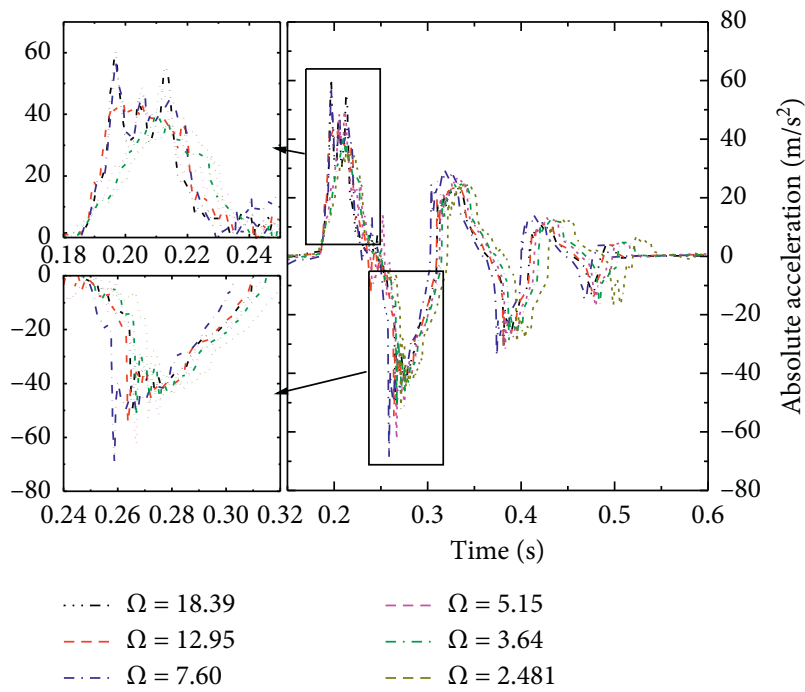

(c)

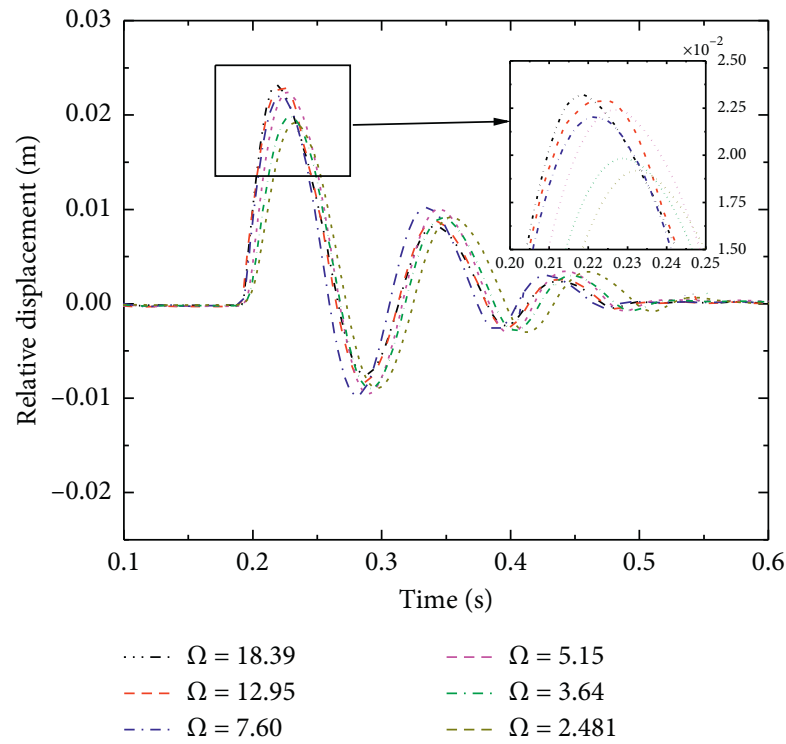

(b)

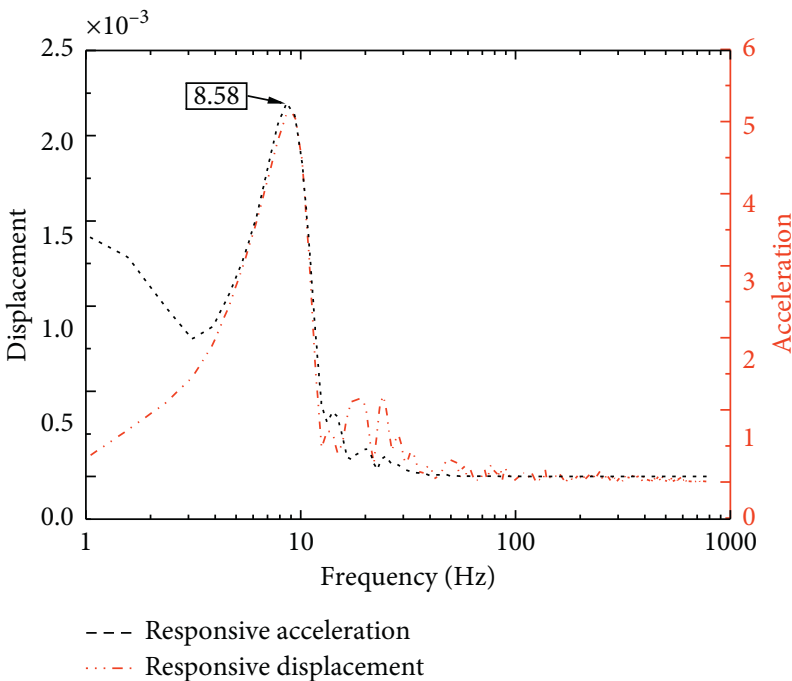

(d)

Figure 17: Time-domain signal of isokinetic shock loads with the dimensionless velocity constant $C^{\prime}=7.40$ and system responses. (a) A series of the time-domain curves of isokinetic shock loads. (b) Absolute acceleration responses of bearing mass. (c) Relative displacement responses of the ODS shock isolation system. (d) Frequency spectra of absolute acceleration and relative displacement signal.

Figure 17(a) shows a series of the time-domain curves of isokinetic shock loads with the dimensionless velocity constant $C^{\prime}=7.40$ (the actual table shock velocity is $1.6 \mathrm{~m} / \mathrm{s}$ ), Figures $17(\mathrm{~b})$ and $17(\mathrm{c})$ show the relative displacement and absolute acceleration responses of bearing mass, and Figure 17(d) shows the FFT spectrum of relative displacement and absolute acceleration response of bearing mass. It can be concluded that when the bearing mass of the ODS shock isolator is $4.46 \mathrm{Kg}$ and the dimensionless velocity constant $C^{\prime}=7.40$, the natural frequency value of the ODS shock isolator is stable at $8.58 \mathrm{~Hz}$ from the FFT spectrum of relative displacement and absolute acceleration response. Therefore, the frequency ratio of the input loads with the dimensionless velocity constant $C^{\prime}=7.40$ can be calculated as $18.39,12.95$, $7.60,5.15,3.64$, and 2.841 , respectively, where $A_{i}(i=1, \ldots, 6)$ in Figure 17(a) is the amplitude of the input load.

To display the characteristics and maximum value of the time history signal of the absolute acceleration response more clearly, the median filtering method is used to postprocess the original signal, and the continuous sampling value is set as 15 . Figure 18 shows the absolute acceleration response time-domain signal generated by the acceleration excitation with the dimensionless velocity constant $C^{\prime}=7.40$ and frequency ratio $\Omega=18.39$ isolated by the ODS shock 


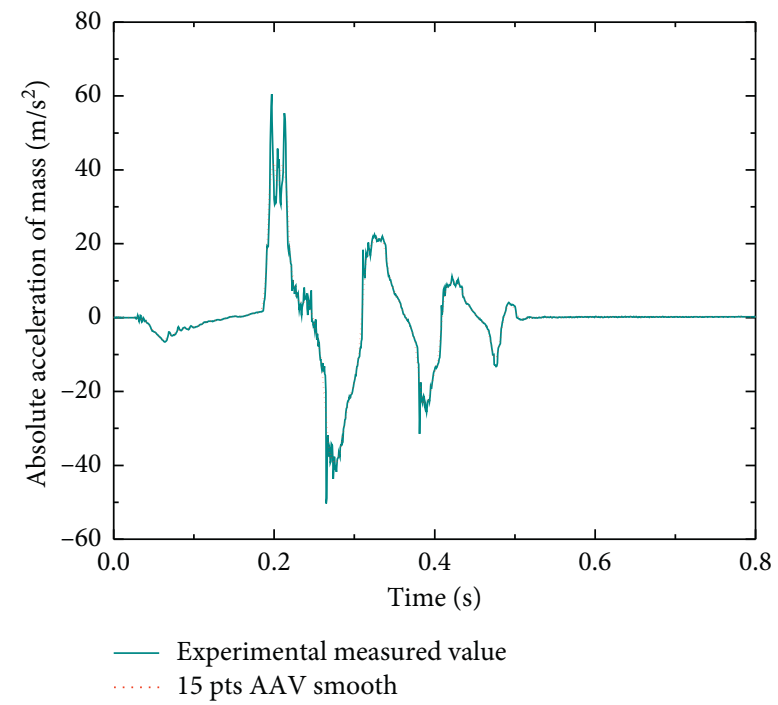

FIgURE 18: The time-domain signal of the absolute acceleration response and the time-domain signal filtered by the median filter.

isolator and the time-domain signal filtered by the median filter. The same time-domain signal postprocessing method is applied to the analysis of other absolute acceleration responses.

Figure 19 shows the relation curve between the maximum absolute value of the relative displacement responses and frequency ratio $\Omega$ of the ODS shock isolation system after shock. The shock input is a series of isokinetic shock loads with the dimensionless velocity constant $C^{\prime}=7.40$ and $C^{\prime}=5.55$, respectively. From the curve trend, it can be clearly observed that when the frequency ratio $\Omega<5$, the maximum absolute value of the relative displacement response increases with the increase of the frequency ratio. However, when $\Omega \geq 5$, whatever the value of the dimensionless velocity constant $C^{\prime}$, the ODS shock isolation system reaches the shock state. Although the maximum absolute values of the relative displacement response fluctuate, the values are generally stable near a certain value. This experimental results show the same law as the simulation results in Section 3 . This suggests that a shock isolation system has a shock state. The system reaches this state when the duration of the base excitation is less than $1 / 5$ of the natural period of the shock isolation system. In this state, the shock load of the isolation system is approximately equivalent to the step velocity load with the same dimensionless velocity constant.

In the actual shock process, there is always a negative wave effect in the shock isolation system, so the ideal halfsine shock input cannot be obtained. The absolute displacement values of the base, which are obtained through quadratic integration of the actual acceleration signal, are quite different from those under the ideal half-sine shock input. Thus, it is of little significance to compare the SDR spectra of simulation and experiment. In this section, the SAR and RDR spectra obtained by experiment and simulation are comparatively analyzed. Figure 20 shows the SAR and RDR spectra of the ODS shock isolation system under shock by a series of isokinetic shock excitation. The

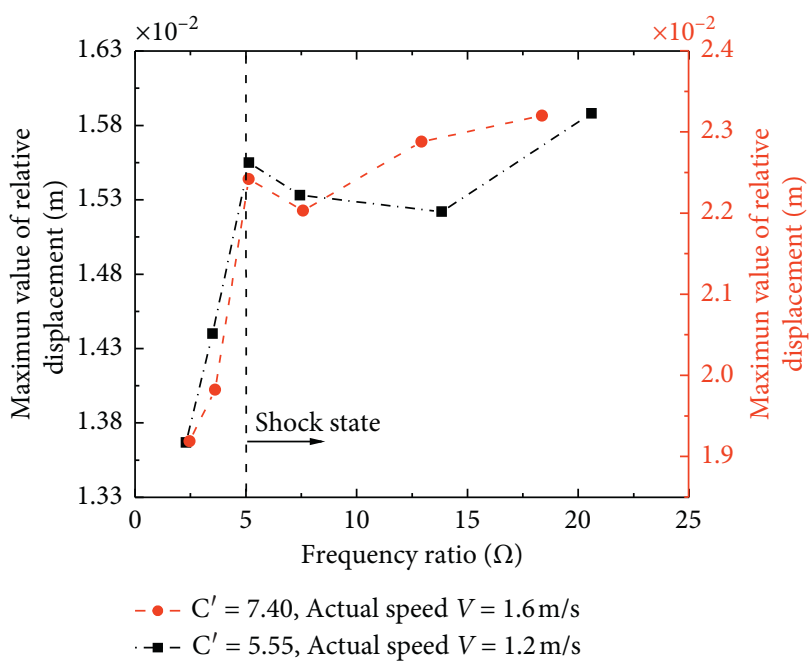

FIGURE 19: The relation curve between the maximum absolute value of the relative displacement responses and the frequency ratio $\Omega$.

dimensionless velocity constant $C^{\prime}$ values of these isokinetic shock excitation are 5.55 and 7.40, respectively. It can be seen in this figure that under the experimental conditions, the response values corresponding to the same frequency ratio in the SAR spectra decrease with the increase of the dimensionless velocity constant $C^{\prime}$, while those corresponding to the same frequency ratio in the RAR spectra increase with the increase of the dimensionless velocity constant $C^{\prime}$. With the increase of the frequency ratio $\Omega$, the response values corresponding to the same dimensionless velocity constant $C^{\prime}$ in the SAR spectra are gradually reduced, while those in the RAR spectrum are gradually increased. This shows that with the increase of the frequency ratio $\Omega$, the isolation performance of the system for acceleration becomes better, while that of the system for relative displacement gets worse. The rules of the isolation 

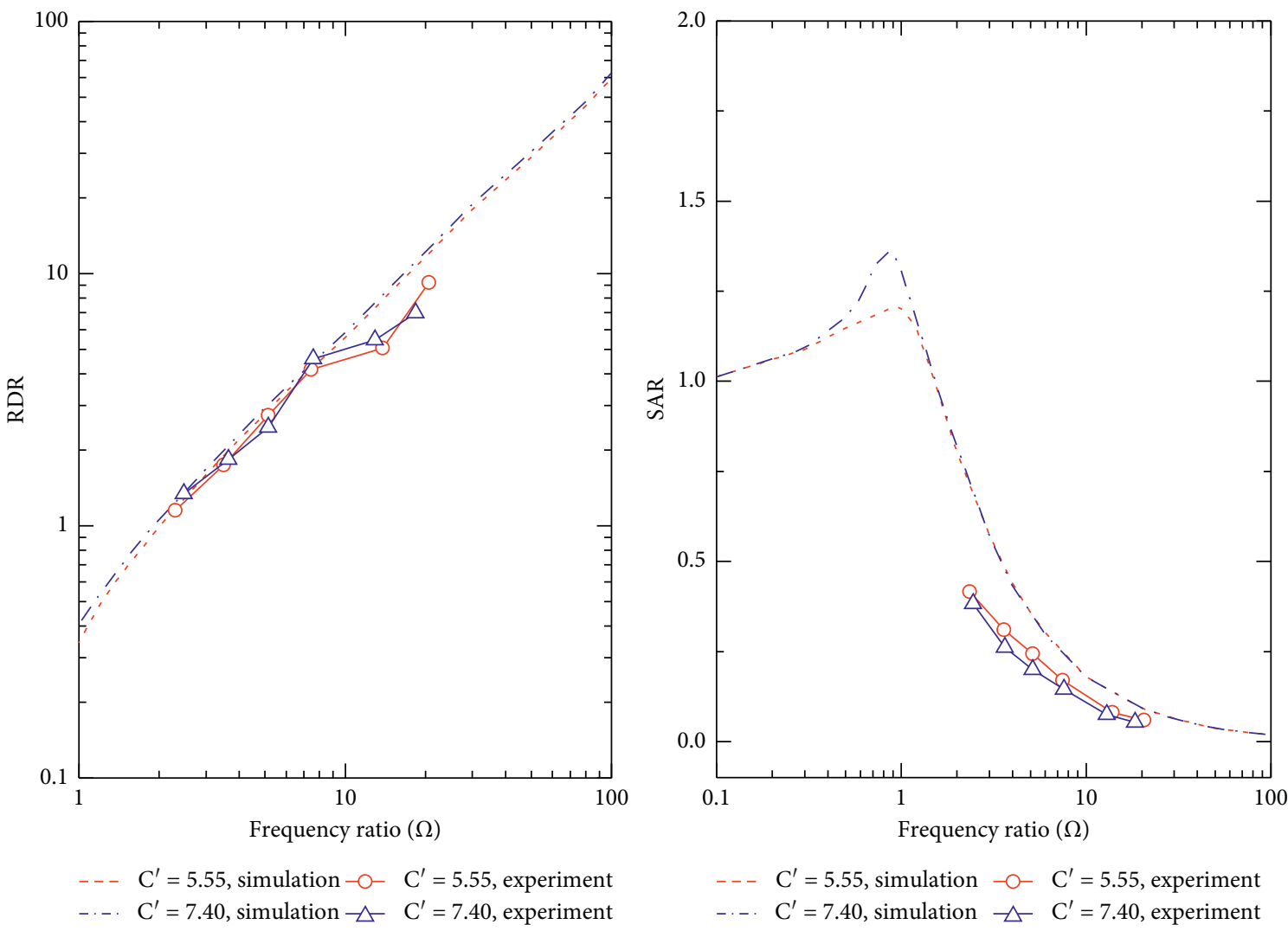

FIgURE 20: The SAR and RDR spectra of the ODS shock isolation system under shock by a series of isokinetic shock excitation.

performance of the system are the same in experiment and simulation.

\section{Conclusion}

Relying on the above numerical and experimental results, conclusions can be drawn as follows:

(1) An additional supporting force is generated by the internal friction of the ODS shock isolator. The direction of the additional supporting force is opposite to that of the system's movement velocity; the magnitude of this force first increases and then decreases with the increase of the axial displacement $x$.

(2) For any shock isolation system, when the duration of the base excitation is less than $1 / 5$ of the natural period of the shock isolation system, the system enters the shock state. In this state, the response form of the system is approximately equivalent to the shock response caused by step load with the same dimensionless velocity constant $C^{\prime}$. The base excitation at this time should be expressed as shock loads. However, when the duration of the base excitation is more than $1 / 5$, the system is out of the shock state. At this point, the system is closer to the forced vibration state. When the duration of the base excitation is much longer than the natural period of the shock isolation system, the system enters the static loading state.
(3) The equivalent average of the additional supporting force of the ODS shock isolator is related to the number of disc springs and friction coefficient and independent of the preload of the system. Under isokinetic shock, when the system enters the shock state, the ODS shock isolator with less disc springs and smaller preload has a better isolation performance for acceleration. With the increase of the frequency ratio $\Omega$, the system has a better isolation efficiency for acceleration but a worse isolation efficiency for displacement.

(4) Under isokinetic shock excitation, when the gravity of the bearing mass is less than the initial bearing capacity of the ODS shock isolator, and the system is in the shock state, the bearing mass exerts weak effects on the SAR, SDR, and RDR of the system. The ODS shock isolation system with heavier bearing load has a slightly better isolation performance for acceleration but a slightly worse isolation performance for displacement. When the gravity of the bearing mass is more than the initial bearing capacity of the ODS shock isolator, with the increase of the bearing mass, the isolation performance of the system for acceleration becomes better, but the effective isolation displacement becomes shorter.

(5) The magnitude of the energy carried by the shock loads have a certain effect on the ODS shock isolation system. When the system reaches the shock state, with the increase of the energy carried by the shock 
loads, the isolation performance of the system for acceleration turns better, but the isolation performance of the system for displacement gets worse. Under isokinetic shock excitation, with the increase of the frequency ratio $\Omega$, the isolation efficiency of the system for acceleration becomes better, while the isolation efficiency of the system for displacement gets worse.

\section{Data Availability}

The data used to support the findings of this study are included within the article.

\section{Conflicts of Interest}

The authors declare that there are no conflicts of interest.

\section{Acknowledgments}

This work was supported by the National Natural Science Foundation of China (51775354) and Liao Ning Revitalization Talents Program of China (XLYC1802007).

\section{References}

[1] C. M. Harris and C. E. Crede, Shock and Vibration Handbook, McGraw-Hill, New York, NY, USA, 4th edition, 1995.

[2] I. Mohd Ikmal and F. Neil Stuart, "Passive shock isolation utilising dry friction," Shock and Vibration, vol. 2017, Article ID 7313809, 21 pages, 2017.

[3] C. T. Morrow, Shock and Vibration Engineering, John Wiley \& Sons, New York, NY, USA, 1963.

[4] L. Gaul and J. Becker, "Reduction of structural vibrations by passive and semiactively controlled friction dampers," Shock and Vibration, vol. 2015, Article ID 870564, 7 pages, 2014.

[5] J. C. Snowdon, "Response of nonlinear shock mountings to transient foundation displacements," The Journal of the Acoustical Society of America, vol. 33, no. 10, pp. 1295-1304, 1961.

[6] D. F. Ledezma-Ramirez, N. S. Ferguson, and M. J. Brennan, "Shock isolation using an isolator with switchable stiffness," Journal of Sound and Vibration, vol. 330, pp. 868-882, 2018.

[7] J. Zhou, Q. Xiao, D. Xu, H. Ouyang, and Y. Li, "A novel quasizero-stiffness strut and its applications in six-degree-offreedom vibration isolation platform," Journal of Sound and Vibration, vol. 394, pp. 59-74, 2017.

[8] J. Zhou, X. Wang, D. Xu, and S. Bishop, "Nonlinear dynamic characteristics of a quasi-zero stiffness vibration isolator with cam-roller-spring mechanisms," Journal of Sound and Vibration, vol. 346, pp. 53-69, 2015.

[9] H. Huang and D. Hui, "Accurate backbone curves for largeamplitude vibrations of imperfect rectangular plate with viscous damping," KSCE Journal of Civil Engineering, vol. 19, no. 5, pp. 1438-1444, 2015.

[10] Q. Wang, J. Zhou, D. Xu, and H. Ouyang, "Design and experimental investigation of ultra-low frequency vibration isolation during neonatal transport," Mechanical Systems and Signal Processing, vol. 139, Article ID 106633, 2020.

[11] K. Wang, J. Zhou, H. Ouyang et al., "A semi-active metamaterial beam with electromagnetic quasi-zero-stiffness resomators for ultralow-frequency band gap tuning,"
International Journal of Mechanical Sciences, vol. 176, Article ID 105548, 2020.

[12] W. Wu, X. Chen, and Y. Shan, "Analysis and experiment of a vibration isolator using a novel magnetic spring with negative stiffness," Journal of Sound and Vibration, vol. 333, pp. 2985-2970, 2014.

[13] C. Duan and R. Singh, "Dynamic analysis of preload nonlinearity in a mechanical oscillator," Journal of Sound and Vibration, vol. 301, no. 3-5, pp. 963-978, 2007.

[14] K. Peleg and S. Hinga, "Simplified determination of stability bounds in nonlinear vibration systems," Journal of Vibration and Acoustics, vol. 114, no. 3, pp. 319-325, 1992.

[15] J. O. Almen and A. Laszlo, "the uniform section disk spring," ASME, vol. 58, pp. 305-314, 1936.

[16] G. L. Rosa and R. Messina, "Tangential and radial stresses of variable thickness Belleville spring," Journal of Mechanical Design, vol. 132, no. 2, pp. 294-2997, 2001.

[17] P. K. Saini, P. Kumar, and P. Tandon, "Design and analysis of radially tapered disc springs with parabolically varying thickness," Proceedings of the Institution of Mechanical Engineers, Part C: Journal of Mechanical Engineering Science, vol. 221, no. 2, pp. 151-158, 2007.

[18] S. Ozaki, K. Tsuda, and J. Tominaga, "Analyses of static and dynamic behavior of coned disk springs: effects of friction boundaries," Thin-Walled Structures, vol. 59, pp. 132-143, 2012.

[19] W. Patangtalo, S. Aimmanee, and S. Chutima, "A unified analysis of isotropic and composite Belleville springs," ThinWalled Structures, vol. 109, pp. 285-295, 2016.

[20] N. Fawazi, I.-H. Yang, J.-S. Kim, J.-Y. Lee, H.-S. Kim, and J.-E. Oh, "An inverse algorithm of nonlinear load-displacement for a slotted disc spring geometric design," International Journal of Precision Engineering and Manufacturing, vol. 14, no. 1, pp. 137-145, 2013.

[21] Y. F. Gao and J. M. Yang, "Dynamic analysis of nonlinear buffer vibration isolation system," Journal of Gun Launch \& Control, vol. 81, pp. 27-30, 2006.

[22] X. T. Liu, X. C. Huang, and H. X. Hua, "Performance of a zero stiffness isolator under shock excitations," Journal of Vibration and Control, vol. 20, pp. 2090-2099, 2014.

[23] B. Tang and M. J. Brennan, "On the shock performance of a nonlinear vibration isolator with high-static-low-dynamicstiffness," International Journal of Mechanical Sciences, vol. 81, no. 1, pp. 207-214, 2014.

[24] Y. Wang and H. X. Hua, Modern Shock Theory and Application of Ships, Science Press, Beijing, China, 2005.

[25] V. M. Ryaboy, "Optimal protection from impact," Shock, and Vibration," Shock and Vibration, vol. 8, Article ID 429808, 2 pages, 2001.

[26] C. M. Harris and A. G. Piersol, Harris' Shock and Vibration Handbook, McGraw-Hill, New York, NY, USA, 2002.

[27] J. C. Snowdon, Vibration and Shock in Damped Mechnical Systems, John Wiley, Hoboken, NJ, USA, 1968.

[28] S. S. Rao, Mechanical Vibration, Prentice-Hall, Upper Saddle River, NJ, USA, 5th edition, 2010.

[29] D. F. Ledezma-Ramirez, N. S. Ferguson, M. J. Brennan, and B. Tang, "An experimental nonlinear low dynamic stiffness device for shock isolation," Journal of Sound and Vibration, vol. 347, pp. 1-13, 2015.

[30] D. F. Ledezma-Ramirez, N. S. Ferguson, and M. J. Brennan, "An experimental switchable stiffness device for shock isolation," Journal of Sound and Vibration, vol. 331, no. 23, pp. 4987-5001, 2012. 